\title{
High Therapeutic and Esthetic Properties of Extracellular Vesicles Produced from the Stem Cells and Their Spheroids Cultured from Ocular Surgery-Derived Waste Orbicularis Oculi Muscle Tissues
}

\author{
Kyung Min Lim ${ }^{1,+}{ }^{\mathbb{D}}$, Ahmed Abdal Dayem ${ }^{1,+}{ }^{\mathbb{D}}$, Yujin Choi ${ }^{1}$, Yoonjoo Lee ${ }^{1}$, Jongyub An ${ }^{1}$, Minchan Gil ${ }^{1}$, \\ Soobin Lee ${ }^{1}$, Hee Jeong Kwak ${ }^{1}{ }^{\mathbb{C}}$, Balachandar Vellingirl ${ }^{2}$, Hyun Jin Shin ${ }^{3, * \mathbb{C}}$ and Ssang-Goo Cho ${ }^{1, * \mathbb{C}}$
}

1 Molecular \& Cellular Reprogramming Center (MCRC), Department of Stem Cell \& Regenerative Biotechnology, Konkuk University, 120 Neungdong-ro, Gwangjin-gu, Seoul 05029, Korea; lmin0217@konkuk.ac.kr (K.M.L.); ahmed_morsy86@yahoo.com (A.A.D.); trikk33@naver.com (Y.C.); leyjo97@gmail.com (Y.L.); delrar@naver.com (J.A.); minchangil@gmail.com (M.G.); soobineey@naver.com (S.L.); h_jeong9581@naver.com (H.J.K.)

2 Human Molecular Cytogenetics and Stem Cell Laboratory, Department of Human Genetics and Molecular Biology, Bharathiar University, Coimbatore 641-046, India; geneticbala@buc.edu.in

3 Department of Ophthalmology, Research Institute of Medical Science, Konkuk University Medical Center, Konkuk University School of Medicine, Seoul 05029, Korea

Citation: Lim, K.M.; Dayem, A.A.; Choi, Y.; Lee, Y.; An, J.; Gil, M.; Lee, S.; Kwak, H.J.; Vellingirl, B.; Shin, H.J.; et al. High Therapeutic and Esthetic Properties of Extracellular Vesicles Produced from the Stem Cells and Their Spheroids Cultured from Ocular Surgery-Derived Waste Orbicularis Oculi Muscle Tissues. Antioxidants 2021, 10, 1292. https:// doi.org/10.3390/antiox10081292

Academic Editor: Ram Kannan

Received: 8 June 2021

Accepted: 8 August 2021

Published: 16 August 2021

Publisher's Note: MDPI stays neutral with regard to jurisdictional claims in published maps and institutional affiliations.

Copyright: () 2021 by the authors. Licensee MDPI, Basel, Switzerland. This article is an open access article distributed under the terms and conditions of the Creative Commons Attribution (CC BY) license (https:// creativecommons.org/licenses/by/ $4.0 /)$.
* Correspondence: shineye@kuh.ac.kr (H.J.S.); ssangoo@konkuk.ac.kr (S.-G.C.)

+ These authors contributed equally to this study.
Abstract: Extracellular vesicles (EVs) are paracrine factors that mediate stem cell therapeutics. We aimed at evaluating the possible therapeutic and esthetic applications of EVs prepared from the waste human facial tissue-derived orbicularis oculi muscle stem cells (OOM-SCs). OOM-SCs were isolated from the ocular tissues (from elders and youngsters) after upper eyelid blepharoplasty or epiblepharon surgeries. EVs were prepared from the OOM-SCs (OOM-SC-EVs) and their threedimensional spheroids. OOM-SCs showed a spindle-like morphology with trilineage differentiation capacity, positive expression of CD105, CD 90, and CD73, and negative expression of CD45 and CD34, and their stem cell properties were compared with other adult mesenchymal stem cells. OOM-SC-EVs showed a high inhibitory effect on melanin synthesis in B16F10 cells by blocking tyrosinase activity. OOM-SC-EVs treatment led to a significant attenuation of senescence-associated changes, a decrease in reactive oxygen species generation, and an upregulation of antioxidant genes. We demonstrated the regeneration activity of OOM-SC-EVs in in vitro wound healing of normal human dermal fibroblasts and upregulation of anti-wrinkle-related genes and confirmed the therapeutic potential of OOM-SC-EVs in the healing of the in vivo wound model. Our study provides promising therapeutic and esthetic applications of OOM-SC-EVs, which can be obtained from the ocular surgery-derived waste human facial tissues.

Keywords: waste orbicularis oculi muscle tissue; OOM-SC extracellular vesicles; anti-senescence; antioxidant; whitening; wound healing

\section{Introduction}

Eyelid blepharoplasty is one of the most commonly performed facial cosmetic procedures [1], and myocutaneous flaps of the orbicularis oculi muscle (OOM) have previously been used to repair facial skin defects of the cheek, nose, and eyelid [2,3]. During these surgeries, however, large amounts of OOM were removed and considered as medical waste. Thus, in this study, we aimed to exploit these waste tissues for the isolation of stem cells with beneficial therapeutic applications.

OOMs, which are rich in vascular distribution, may have regenerative capacity and play vital roles in tissue grafting and facial burn injury repair [4]. Recent reports have 
shown the efficacy of the ocular muscle tissue as a rich source of stem cells with high proliferation, differentiation, and therapeutic capacities [5-9]. In this regard, OOM-derived stem cells (OOM-SCs) have garnered much attention and application recently for disease therapy and tissue regeneration due to their self-renewal, proliferation, and trilineage differentiation capacities [10].

Extracellular vesicles (EVs) are nano-sized vesicles (approximately $30-150 \mathrm{~nm}$ ) which play vital roles in cell-cell communication, transportation of key molecules between cells, and maintenance of homeostasis [11-17]. Few studies have shown the possible clinical applications of stem cell-derived EVs in the treatment of various diseases [18-21]. EVs and secretomes are components of paramount importance in mesenchymal stem cell (MSC)-associated paracrine action and subsequent regenerative capacities [22-25]. It is of note that various reports have shown the implications of MSC-derived EVs in tissue regeneration [26-28]. Applications of EVs in disease therapy provide several merits over the parent cells, including the ease of handling and storing at $-70{ }^{\circ} \mathrm{C}$ for a long time, the enhanced binding capacity with the target cells, the reduced immune rejection and tumor formation, the ease of sterilizing via filtration before injection, and the convenience of handling EVs during therapy because of, for instance, easy to control EVs dose and injection route [29-34].

EVs are considered as the fingerprints of the original parent cells due to the dependence of their composition and properties on the composition and characteristics of the producing parent cells and could indicate their biological functions in the regeneration of target tissues or organs [35-37]. Regardless of the parent cell source, EV-associated markers, which depend on the presence or absence of specific proteins, could determine their purity and unique characteristics $[35,36]$.

EVs possess specific proteins and microRNA (miRNA), which are implicated in EVassociated biological functions [38-40]. Moreover, EV-associated lipids are involved in EV-mediated anti-cancer activity and particular lipids possess angiogenic, mitogenic, migratory, and immunomodulatory activities that are consequently useful for healing incurable skin wounds [41,42]. It is of note that the capacity of human MSCs (hMSCs)derived EVs in the healing of skin wounds is attributed to their robust involvement in regulating cellular proliferation, extracellular matrix remodeling, inflammatory events, angiogenesis, and activation of specific signaling pathways [27,43-46]. Various reports have proved the crosslink between EVs and the modulation of pathophysiological events in the skin [34,47].

In the present study, we examined the characteristics of OOM-SCs in terms of expression of surface markers, stemness markers expression level, colony-forming, and trilineage differentiation capacities in comparison to other MSCs such as human umbilical cord Wharton's jelly-MSCs (WJ-MSCs), human adipose-derived MSCs (AD-MSCs), and human urine-derived stem cells (USCs). Then, we tried to investigate the therapeutic and esthetic applications of OOM-SC-derived EVs (OOM-SC-EVs) that were purified from OOM-SCs, which were isolated from the ocular surgery-derived waste of human facial tissues from both youngsters and elders. Our results may indicate the possible applications of OOM-SC-EVs for esthetic and reconstructive purposes, which are outlined in Figure 1A. 
A


Anti-Oxidant

Ultrafiltration system

Ultracentrifuge

Stem cell-derived EVs

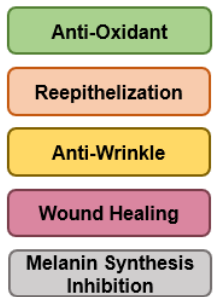

C
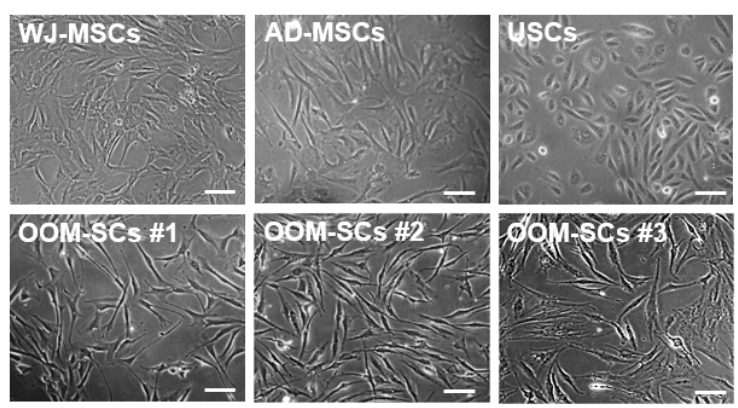

D

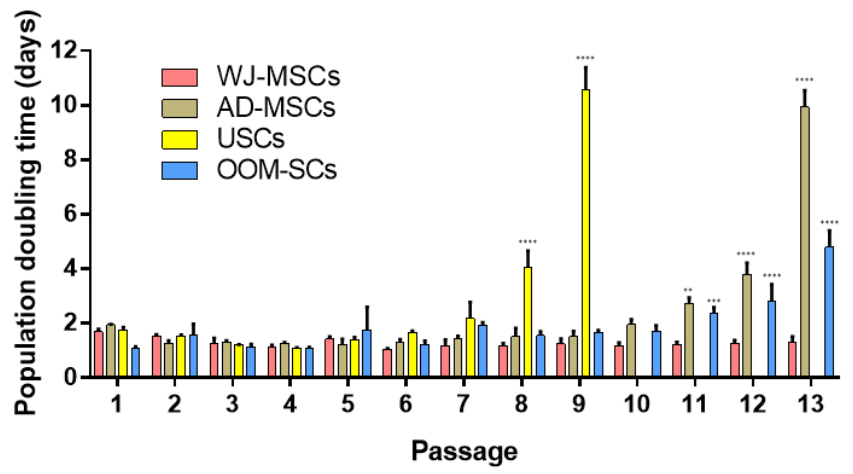

E

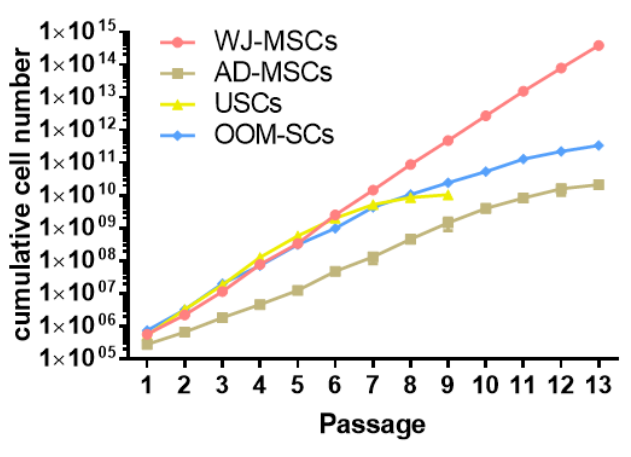

Figure 1. Schematic representation for application of novel OOM-SC-EVs and OOM-SCs preparation. (A) Schematic representation of isolation of stem cells from various sources, such as OOM, adipose tissue, Wharton's Jelly, and urine and then their characterization, which were carried out via the enzymatic digestion using collagenase type II. USCs were obtained via centrifugation at $400 \times g$, and purification of EVs from OOM-SCs and WJ-MSCs using differential centrifugation, ultrafiltration, and ultracentrifugation. Our study sought the therapeutic applications of the purified EVs including antioxidant, anti-senescence, whitening, and wound healing. OOM-SC-EVs were isolated from the collected culture soup of the OOM-SCs cultured in $\alpha$-MEM medium containing exosome-depleted $10 \%$ FBS for two days, which were 
subjected to differential centrifugation, vacuum filtration, ultrafiltration, and ultracentrifugation for EVs purification. The antioxidant, anti-wrinkling, skin whitening, and in vitro and in vivo wound healing activities of the OOM-SC-EVs were observed. These vesicles can be further applied for therapeutic applications in combination with microneedles. Parts of the schematic diagram are created with BioRender.com. (B) Figure illustrating the upper eyelid blepharoplasty for the isolation of pretarsal OOM after the consent of donors. OOM-SCs were prepared from healthy donors. (C) Morphologies of WJ-MSCs, AD-MSCs, USCs, and OOM-SCs (isolated from different donors (OOM-SCs \#1(5y), OOM-SCs\#2 (19y), and OOM-SCs\#3 (67y)). Phase-contrast microscopic image of isolated cells that showing spindle-like morphologies. Scale bar $=50 \mu \mathrm{m}$. OOM-SC proliferation kinetics including (D) population doubling time and (E) Cumulative cell number of WJ-MSCs, AD-MSCs, USCs, and OOM-SCs. Cell population doubling time was measured up to passage 13. For cumulative cell number, cells were counted using a hemocytometer after staining with $0.4 \%$ trypan blue under a phase contrast microscope. Figure 1D data are presented as mean \pm SD. All experiments were performed for three independent times, and statistical significance was determined using RMANOVA: ${ }^{* *} p<0.01$, ${ }^{* * *} p<0.001$, and ${ }^{* * *} p<0.0001$.

\section{Materials and Methods}

\subsection{Preparation and Culture of OOM-SCs, WJ-MSCs, AD-MSCs, and USCs}

The experimental protocols for isolation of OOMs and orbicularis oculi fats (OOFs) were approved by the ethics committees of Konkuk University Medical Center (IRB number: KUMC 2019-05-043) and conformed to the principles outlined in the Declaration of Helsinki. For the preparation of OOM-SCs and OOF-derived cells (OOFCs), 16 donors who underwent eyelid blepharoplasty were enrolled in this study; age ranged from 5-year-old to 81-year-old males and females and is listed in detail in supplementary Table 1. All patients provided written informed consent and did not present any other ocular/orbital pathology (dermatochalasis, entropion, and epiblepharon). Muscle fragments were obtained from the pretarsal portion of the OOM during the surgery. Human OOMs and OOFs were washed twice with phosphate-buffered saline (PBS) containing $50 \mu \mathrm{g} / \mathrm{mL}$ gentamicin, and the clotted blood was removed to avoid tissue contamination and blood clots. The tissues were then chopped with a sterile blade and incubated with $4 \mathrm{mg} / \mathrm{mL}$ of collagenase type II (Worthington, LS004176) at $37^{\circ} \mathrm{C}$ for $90 \mathrm{~min}$ with intermittent shaking every 5 min to obtain single cells. After the end of the incubation period, we centrifuged the digested tissues twice at $400 \times g$ for $10 \mathrm{~min}$ to remove the supernatant containing the remaining collagenase. We then suspended the tissue pellets with the alpha-minimum essential medium ( $\alpha$-MEM) (Gibco, Gaithersburg, MD, USA) supplemented with 10\% fetal bovine serum (FBS, Hyclone, Logan, UT, USA) and 1\% penicillin/streptomycin (PS, Gibco), seeded onto $0.2 \%$ gelatin-coated culture dish, and incubated at $37{ }^{\circ} \mathrm{C}$ in $5 \% \mathrm{CO}_{2}$ with the continuous microscopic observation of cell adherence and morphology.

Table 1. Primer sequences of the genes used in this study.

\begin{tabular}{|c|c|c|c|}
\hline $\begin{array}{c}\text { Gene } \\
\text { (Application) }\end{array}$ & $\begin{array}{c}\text { NCBI } \\
\text { Accession Number }\end{array}$ & $\begin{array}{l}\text { Forward Primer }\left(5^{\prime} \text { to } 3^{\prime}\right) \\
\text { Reverse Primer }\left(5^{\prime} \text { to } 3^{\prime}\right)\end{array}$ & Product Length $(b p)$ \\
\hline $\begin{array}{c}\text { NANOG } \\
\text { (Semi-qPCR) }\end{array}$ & NM_001355281.2 & $\begin{array}{c}\text { TCCTGAACCTCAGCTACAAAC } \\
\text { GCGTCACACCATTGCTATTC }\end{array}$ & 108 \\
\hline $\begin{array}{c}\text { SOX2 } \\
\text { (Semi-qPCR) }\end{array}$ & NM_003106.4 & $\begin{array}{l}\text { CATCACCCACAGCAAATGAC } \\
\text { GAAGTCCAGGATCTCTCTCATAAA }\end{array}$ & 110 \\
\hline $\begin{array}{c}\text { REX1 } \\
\text { (Semi-qPCR) }\end{array}$ & NM_001304358.2 & $\begin{array}{l}\text { GTTTCGTGTGTCCCTTTCAAG } \\
\text { CTGTTATCTGCTTCATCCTGTTG }\end{array}$ & 141 \\
\hline $\begin{array}{c}\text { ITGA6 } \\
\text { (Semi-qPCR) }\end{array}$ & NM_001394928.1 & $\begin{array}{l}\text { CGAAACCAAGGTTCTGAGCCCA } \\
\text { CTTGGATCTCCACTGAGGCAGT }\end{array}$ & 151 \\
\hline $\begin{array}{c}\text { CD146 } \\
\text { (Semi-qPCR) }\end{array}$ & NM_006500.3 & $\begin{array}{c}\text { GTGTTGAATCTGTCTTGTGAA } \\
\text { ATGCCTCAGATCGATG }\end{array}$ & 600,419 \\
\hline $\begin{array}{c}\text { TM4SF1 } \\
\text { (Semi-qPCR) }\end{array}$ & NM_014220.3 & $\begin{array}{l}\text { GGCTACTGTGTCATTGTGGCAG } \\
\text { ACTCGGACCATGTGGAGGTATC }\end{array}$ & 133 \\
\hline $\begin{array}{c}\text { CD19 } \\
\text { (Semi-qPCR) }\end{array}$ & NM_001385732.1 & $\begin{array}{l}\text { CCTGGGGTCCCAGTCCTATG } \\
\text { GCTCCAGAGGTTGGCATCAT }\end{array}$ & 287 \\
\hline
\end{tabular}


Table 1. Cont.

\begin{tabular}{|c|c|c|c|}
\hline $\begin{array}{c}\text { Gene } \\
\text { (Application) }\end{array}$ & $\begin{array}{c}\text { NCBI } \\
\text { Accession Number }\end{array}$ & $\begin{array}{l}\text { Forward Primer }\left(5^{\prime} \text { to } 3^{\prime}\right) \\
\text { Reverse Primer }\left(5^{\prime} \text { to } 3^{\prime}\right)\end{array}$ & Product Length $(b p)$ \\
\hline $\begin{array}{c}\text { CD45 } \\
\text { (Semi-qPCR) }\end{array}$ & NM_080921.4 & $\begin{array}{l}\text { TCAGTGGTCCCATTGTTGTG } \\
\text { GCATCTCTGTGGCCTTAGCT }\end{array}$ & 146 \\
\hline $\begin{array}{c}\text { CD29 } \\
\text { (Semi-qPCR) }\end{array}$ & NM_002211.4 & $\begin{array}{c}\text { GCCGCGCGGAAAAGATG } \\
\text { ACATCGTGCAGAAGTAGGCA }\end{array}$ & 206 \\
\hline $\begin{array}{c}\text { CD73 } \\
\text { (Semi-qPCR) }\end{array}$ & NM_002526.4 & $\begin{array}{l}\text { TATCCGGTCGCCCATTGATG } \\
\text { ACGCTATGCTCAAAGGCCTT }\end{array}$ & 138 \\
\hline $\begin{array}{c}\text { CD105 } \\
\text { (Semi-qPCR) }\end{array}$ & NM_001278138.2 & $\begin{array}{l}\text { CCAAGACCGGGTCTCAAGAC } \\
\text { TGTACCAGAGTGCAGCAGTG }\end{array}$ & 174 \\
\hline $\begin{array}{c}\text { CD166 } \\
\text { (Semi-qPCR) }\end{array}$ & NM_001627.4 & $\begin{array}{l}\text { GAACACGATGAGGCAGACGA } \\
\text { CCGAGGTCCTTGTTTACATGTTT }\end{array}$ & 179 \\
\hline $\begin{array}{c}\text { GAPDH } \\
\text { (Semi-qPCR) }\end{array}$ & NM_001357943.2 & $\begin{array}{c}\text { AATCCCATCACCATCTTCCAG } \\
\text { ATGACCCTTTTGGCTCCC }\end{array}$ & 146 \\
\hline $\begin{array}{c}\text { GPX1 } \\
\text { (qPCR) }\end{array}$ & NM_001329503.2 & $\begin{array}{c}\text { CAGTCGGTGTATGCCTTCTCG } \\
\text { GAGGGACGCCACATTCTCG }\end{array}$ & 105 \\
\hline $\begin{array}{c}\text { GPX2 } \\
\text { (qPCR) }\end{array}$ & NM_002083.4 & $\begin{array}{l}\text { GGTAGATTTCAATACGTTCCGGG } \\
\text { TGACAGTTCTCCTGATGTCCAAA }\end{array}$ & 174 \\
\hline $\begin{array}{l}\text { GPX3 } \\
(q P C R)\end{array}$ & NM_001329790.2 & $\begin{array}{l}\text { AGAGCCGGGGACAAGAGAA } \\
\text { ATTTGCCAGCATACTGCTTGA }\end{array}$ & 153 \\
\hline $\begin{array}{l}\text { GPX4 } \\
(q P C R)\end{array}$ & NM_001367832.1 & $\begin{array}{l}\text { GAGGCAAGACCGAAGTAAACTAC } \\
\text { CCGAACTGGTTACACGGGAA }\end{array}$ & 100 \\
\hline $\begin{array}{l}\text { GPX7 } \\
(q P C R)\end{array}$ & NM_015696.5 & $\begin{array}{l}\text { CCCACCACTTTAACGTGCTC } \\
\text { GGCAAAGCTCTCAATCTCCTT }\end{array}$ & 86 \\
\hline $\begin{array}{c}\text { GSR } \\
\text { (qPCR) }\end{array}$ & NM_001195102.3 & $\begin{array}{l}\text { TTCCAGAATACCAACGTCAAAGG } \\
\text { GTTTTCGGCCAGCAGCTATTG }\end{array}$ & 94 \\
\hline $\begin{array}{c}\text { SOD1 } \\
\text { (qPCR) }\end{array}$ & NM_000454.5 & $\begin{array}{l}\text { GGTGGGCCAAAGGATGAAGAG } \\
\text { CCACAAGCCAAACGACTTCC }\end{array}$ & 227 \\
\hline $\begin{array}{l}\text { SOD2 } \\
\text { (qPCR) }\end{array}$ & NM_001322816.2 & $\begin{array}{l}\text { GCTCCGGTTTTGGGGTATCTG } \\
\text { GCGTTGATGTGAGGTTCCAG }\end{array}$ & 92 \\
\hline $\begin{array}{l}\text { SOD3 } \\
\text { (qPCR) }\end{array}$ & NM_003102.4 & $\begin{array}{l}\text { ATGCTGGCGCTACTGTGTTC } \\
\text { CTCCGCCGAGTCAGAGTTG }\end{array}$ & 99 \\
\hline $\begin{array}{l}\text { Catalase } \\
\text { (qPCR) }\end{array}$ & NM_001752.4 & $\begin{array}{l}\text { TGTTGCTGGAGAATCGGGTTC } \\
\text { TCCCAGTTACCATCTTCTGTGTA }\end{array}$ & 87 \\
\hline $\begin{array}{c}\text { TMX1 } \\
\text { (qPCR) }\end{array}$ & NM_030755.5 & $\begin{array}{l}\text { AGTATGTCAGCACTCTTTCAGC } \\
\text { CACACTGGCAATCCAAGGTCT }\end{array}$ & 83 \\
\hline $\begin{array}{l}\text { TXNIP } \\
\text { (qPCR) }\end{array}$ & NM_006472.6 & $\begin{array}{l}\text { GGTCTTTAACGACCCTGAAAAGG } \\
\text { ACACGAGTAACTTCACACACCT }\end{array}$ & 87 \\
\hline $\begin{array}{c}\text { TXN } \\
\text { (qPCR) }\end{array}$ & NM_001244938.2 & $\begin{array}{l}\text { GTGAAGCAGATCGAGAGCAAG } \\
\text { CGTGGCTGAGAAGTCAACTACTA }\end{array}$ & 87 \\
\hline $\begin{array}{l}\text { Col1A1 } \\
\text { (qPCR) }\end{array}$ & NM_000088.4 & $\begin{array}{l}\text { GATTCCCTGGACCTAAAGGTGC } \\
\text { AGCCTCTCCATCTTTGCCAGCA }\end{array}$ & 107 \\
\hline $\begin{array}{l}\text { MCP-1 } \\
\text { (qPCR) }\end{array}$ & NM_002982.4 & $\begin{array}{l}\text { AGAATCACCAGCAGCAAGTGTCC } \\
\text { TCCTGAACCCACTTCTGCTTGG }\end{array}$ & 98 \\
\hline $\begin{array}{l}\text { MCP-3 } \\
\text { (qPCR) }\end{array}$ & NM_006273.4 & $\begin{array}{l}\text { ACAGAAGGACCACCAGTAGCCA } \\
\text { GGTGCTTCATAAAGTCCTGGACC }\end{array}$ & 117 \\
\hline $\begin{array}{l}\text { CCL5 } \\
\text { (qPCR) }\end{array}$ & NM_002985.3 & $\begin{array}{l}\text { CCTGCTGCTTTGCCTACATTGC } \\
\text { ACACACTTGGCGGTTCTTTCGG }\end{array}$ & 125 \\
\hline $\begin{array}{l}\text { PAI-1 } \\
\text { (qPCR) }\end{array}$ & NM_001386456.1 & $\begin{array}{l}\text { CTCATCAGCCACTGGAAAGGCA } \\
\text { GACTCGTGAAGTCAGCCTGAAAC }\end{array}$ & 154 \\
\hline $\begin{array}{l}\text { TGF- } \beta 1 \\
\text { (qPCR) }\end{array}$ & NM_000660.7 & $\begin{array}{l}\text { TACCTGAACCCGTGTTGCTCTC } \\
\text { GTTGCTGAGGTATCGCCAGGAA }\end{array}$ & 122 \\
\hline $\begin{array}{l}\text { TGF- } \beta 3 \\
\text { (qPCR) }\end{array}$ & NM_001329939.2 & $\begin{array}{l}\text { CTAAGCGGAATGAGCAGAGGATC } \\
\text { TCTCAACAGCCACTCACGCACA }\end{array}$ & 161 \\
\hline $\begin{array}{l}\text { GAPDH } \\
\text { (qPCR) }\end{array}$ & NM_001357943.2 & $\begin{array}{l}\text { GTCTCCTCTGACTTCAACAGCG } \\
\text { ACCACCCTGTTGCTGTAGCCAA }\end{array}$ & 131 \\
\hline
\end{tabular}

For the preparation of WJ-MSCs, a human umbilical cord was procured from Konkuk University Hospital after approval by the IRB (7001355-201705-BR-181) of Konkuk Uni- 
versity. The tissues were chopped and the cells from the tissues were cultured in $\alpha$-MEM supplemented with 10\% FBS and 1\% PS. The isolation and characterization of AD-MSCs and USCs were carried out as described in our recent publication [48].

\subsection{Cell Growth Kinetics, Viability and Colony Formation Assays}

Cell growth kinetics were estimated according to population doubling time (PDT) and cumulative cell number. Briefly, cells were seeded at the density of $1 \times 10^{5}$ cells onto a $60 \times 15 \mathrm{~mm}$ culture plate (SPL, 20060, Pocheon-si, Gyeonggi-do, Korea) and incubated at $37{ }^{\circ} \mathrm{C}$ and $5 \% \mathrm{CO}_{2}$ until reaching 80-90\% confluence. Cells were harvested after each passage $(\mathrm{P})$, stained with $0.4 \%$ trypan blue solution, and counted using a hemocytometer under a phase-contrast microscope. Cell population doubling was calculated as reported previously [49] and according to the following equation: $\mathrm{No}(\mathrm{PD})=(\log \mathrm{Nt}-\log \mathrm{N} 0) / 0.301$, where PD represents population doubling, Nt denotes cell number after trypsinization/collection of cells, and N0 indicates the number of seeded cells.

For estimation the effect of EVs in the viability of B16F10 melanoma cells, cells were seeded at $3 \times 10^{3}$ cells / well onto a 96-well plate (SPL, 30096) and incubated at $37^{\circ} \mathrm{C}$ and $5 \%$ $\mathrm{CO}_{2}$ overnight. Cells were then exposed to OOM-SC-EVs in a dose-dependent manner for $24 \mathrm{~h}$. Afterward, cells were treated with $10 \mu \mathrm{L}$ of CCK-8 solution/well (Dojindo, CK04-05, Rockville, MD, USA) and then incubated for $2 \mathrm{~h}$ with protection from light. The absorbance was measured at the wavelength of $450 \mathrm{~nm}$ using a Bio-RAD x-MarkTM spectrophotometer (Bio-Rad Laboratories, Hercules, California, USA). To measure the self-renewal ability of the stem cells, colony-forming units (CFU) were assessed. Stem cells were seeded at $1 \times 10^{3}$ cells per well in 6-well plates (SPL, 32006) and incubated at $37^{\circ} \mathrm{C}$ and $5 \% \mathrm{CO}_{2}$ for 14 days. Following incubation, the cells were washed and stained with $0.15 \%$ crystal violet solution. After washing with PBS, we captured images of the colonies using a microscope (Carl Zeiss).

\subsection{Reverse Transcription Polymerase Chain Reaction (RT-PCR) and Quantitiative PCR (qPCR) Analyses}

Total RNA was isolated from the cells using Labozol Reagent (LaboPass, CMRZ001, Yuseong-gu, Daejeon, Korea) according to the manufacturer's instructions, and the quantification of the purified RNA was performed using a NanoDrop spectrophotometer (Nanodrop Technologies Inc., Wilmington, DE, USA). cDNA synthesis was performed from $2 \mu \mathrm{g}$ total RNA using the M-MuLV reverse transcription kit (Labopass, CMRT010) and oligo dT primers. PCR was performed using rTaq Plus $5 \times$ PCR Master Mix (ELPISBIOTECH, EBT-1319, Seo-gu, Daejeon, Korea), and PCR products were visualized with 1-2\% agarose gels. We performed quantitative real-time PCR via the estimation of the expression changes using the EzAmp ${ }^{\mathrm{TM}}$ qPCR $2 \times$ Master Mix (ELPISBIOTECH, EBT-1802) and an Applied Biosystems 7500 real-time PCR system. We then normalized the expression level of target genes to the housekeeping gene glyceraldehyde 3-phosphate dehydrogenase (GAPDH), and the relative expression was calculated based on the comparative $2^{(-\Delta \Delta \mathrm{Ct})}$ method as reported [50]. The primer sequences for the genes analyzed in this study are shown in Table 1.

\subsection{Flow Cytometry}

Immunophenotyping analysis of OOM-SCs was performed using flow cytometry. Briefly, cells were trypsinized to obtain a single cell suspension and bound with the following primary and secondary antibodies for 10 min on ice. The primary antibodies were used against the following: CD34 (R\&D system, Minneapolis, MN, MAB72271), CD45 PD7/26/16 + 2B11 (Invitrogen, Waltham, MA, USA, MA5-13197), CD73/NT5E (Invitrogen, RG235718), CD90/Thy1 (R\&D system, AF2067), CD105 (Invitrogen, MA5-11854).

We incubated $1 \times 10^{9}$ particles with CD9 magnetic beads (human exosome-Human CD9 flow detection reagent with Dynabeads ${ }^{\circledR}$ magnetic separation technology; Invitrogen, 10620D) overnight at $4{ }^{\circ} \mathrm{C}$ for flow cytometry measurement. Next, the mixture was sub- 
jected to brief centrifugation that was followed by washing before using the measurement with the flow cytometry. The antibodies used in the flow cytometry analysis were against the following: CD63-PE (BD Pharmingen, 556020), and CD81-APC (Miltenyi Biotec B.V. \& Co. KG, Bergisch Gladbach, Germany, 130-119-787). A flow cytometer (BD Bioscience, San Jose, CA, USA) was used to measure the fluorescence intensity generated by the fluorescent labeled antibody.

\subsection{Trilineage Differentiation}

The trilineage differentiation capacities of the isolated stem cells were estimated via the induction of osteogenic, chondrogenic, and adipogenic differentiation. For osteogenic induction, cells were seeded at $5 \times 10^{4}$ cells/well in 24-well plates and exposed for two weeks to the osteogenic differentiation medium containing 10\% Dulbecco's Modified Eagle Medium (DMEM) low glucose medium supplemented with $50 \mu \mathrm{g} / \mathrm{mL}$ L-ascorbic acid 2-phosphate (Sigma, St. Louis, MO, USA), $10 \mathrm{nM} \beta$-glycerophosphate (Sigma), and $100 \mathrm{nM}$ dexamethasone (Sigma). Osteogenic capacity was measured using Alizarin Red S staining (Sigma) to visualize calcium mineralization.

For chondrogenic differentiation, cells were seeded at a density of $5 \times 10^{4}$ cells / well in a 24-well plate and exposed to induction medium, which was composed of $10 \%$ DMEM low glucose medium containing $100 \mathrm{nM}$ dexamethasone, $10 \mathrm{nM} \beta$-glycerophosphate, $50 \mu \mathrm{g} / \mathrm{mL}$ L-ascorbic acid 2-phosphate, $10 \mu \mathrm{g} / \mathrm{mL}$ transforming growth factor- $\beta 1$ (Sigma), $1 \mathrm{mM}$ sodium pyruvate (Sigma), $40 \mu \mathrm{g} / \mathrm{mL}$ proline, and $1 \times$ insulin-transferrin-selenium (Sigma). The chondrogenic differentiation capacity was evaluated via Alcian Blue staining (Sigma).

For adipogenic differentiation, cells were seeded at $5 \times 10^{4}$ cells /well in a 24 -well plate and then exposed to adipogenic differentiation medium containing 10\% DMEM low glucose medium supplemented with $10 \mu \mathrm{g} / \mathrm{mL}$ insulin, $500 \mu \mathrm{M}$ isobutylmethylxanthine (Sigma), $100 \mu \mathrm{M}$ indomethacin (Sigma), and $1 \mu \mathrm{M}$ dexamethasone. The adipogenic differentiation capacity was evaluated using Oil Red O staining (Sigma) to visualize the fat droplets.

\subsection{OOM-SC-EV and WJ-MSC-EV Isolation and Characterization}

For the isolation of EVs, OOM-SCs or WJ-MSCs were seeded at $1 \times 10^{6}$ onto $150-\mathrm{mm}$ cell culture dishes with $\alpha$-MEM medium containing 10\% FBS for two days. After reaching 80-90\% confluence, we changed the media using a 10\% EV-depleted FBS medium, in which the exosome was depleted as described previously [51] for EV isolation. To prepare the EV-depleted FBS, the FBS was subjected to ultracentrifugation at $120,000 \times g$ for $18 \mathrm{~h}$ (Optima L-90K ultracentrifuge, SW32.1 rotor, k-factor 229, Beckman Coulter, Indianapolis, IN, USA). During all the in vitro evaluation experiments of stem cell-derived EVs using various cell lines, we changed the basic culture media to $10 \%$ EV-depleted FBS medium that is used for EVs treatment. The culture medium was collected and subjected to differential centrifugation at $300 \times g$ for 10 min for cell depletion. Subsequently, the supernatant was carefully transferred to a new tube and centrifuged at $2000 \times g$ for $10 \mathrm{~min}$ to remove cell debris. We then transferred the supernatant to a new tube and centrifuged it at $20,000 \times g$ for $1 \mathrm{~h}$. Subsequently, the resultant supernatant was subjected to filtration using a $0.22-\mu \mathrm{m}$ vacuum filter (EMD Millipore SCGP00525 Steriflip-GP Filter), and the subsequent filtrate was subjected to ultrafiltration with an Equilibrate Amicon ${ }^{\circledR}$ Ultra-15 filter (\#UFC901024, $10 \mathrm{kDa}$ MWCO). Finally, EVs pellets prepared via ultracentrifugation $(100,000 \times g$, for $2 \mathrm{~h})$ were suspended in $100 \mu \mathrm{L}$ PBS.

The size of the EVs was determined using dynamic light scattering (DLS) analysis using a Nano Zetasizer (Malvern Instruments, Malvern, UK), and the number of EVs was counted with a nanoparticle tracking analyzer NS300 (NTA, Nanosight, Amesbury, UK) using the following settings: number of captures: four, capture duration: 30 s, Screen gain: 12, camera level: 11 , threshold: two, and temperature: $25^{\circ} \mathrm{C}$.

Further, the morphology and structure of EVs were analyzed by transmission electron microscopy (TEM) at $80 \mathrm{kV}$ (JEM-1010, Nippon Denshi, Tokyo, Japan). We then measured the protein concentration of OOM-SC-EVs using a BCA protein assay kit (Pierce, Waltham, 
MA, USA) according to the manufacturer's protocol. We used $3 \mu \mathrm{g}$ of OOM-SC-EVs protein for western blotting analysis for EV-associated markers.

\subsection{Western Blotting Assay}

We measured the protein levels of the isolated EVs using the BCA protein assay kit according to the manufacturer's protocol. We extracted the cellular proteins using a buffer composed of $100 \mathrm{mM}$ Tris- $\mathrm{HCl}$ (pH 7.5), 1\% Triton X-100 (Sigma), $10 \mathrm{mM} \mathrm{NaCl}$, 10\% glycerol (Amresco, Solon, OH, USA), $50 \mathrm{mM}$ sodium fluoride (Sigma), $1 \mathrm{mM}$ phenylmethylsulfonyl fluoride (PMSF; Sigma), $1 \mathrm{mM}$ p-nitrophenyl phosphate (Sigma), and $1 \mathrm{mM}$ sodium orthovanadate (Sigma). The cell lysates were then centrifuged at 13,000 rpm for $15 \mathrm{~min}$ at $4{ }^{\circ} \mathrm{C}$. The supernatant was carefully transferred into a new E-tube, and protein quantification was performed using a BCA protein assay kit. The proteins $(3 \mu \mathrm{g})$ were separated by $8-12 \%$ sodium dodecyl sulfate polyacrylamide gel electrophoresis (SDS-PAGE) and then transferred onto nitrocellulose membranes (Bio-Rad). Membranes were blocked using $5 \%$ skimmed milk in Tris-buffered saline for $1 \mathrm{~h}$, followed by incubation overnight at $4{ }^{\circ} \mathrm{C}$ with the appropriate primary antibodies (Abs): anti-CD9 (Abcam, ab263023), antiCD63 (Invitrogen, 10628D), anti-CD81 (Santa Cruz, sc-7637), anti-calnexin (CST, 2679T), anti-GM130 (CST, 12480S), and anti- $\beta$-actin (CST, 4970S). Subsequently, the membranes were incubated with secondary antibodies (anti-mouse or -rabbit IgGs), which were conjugated with horseradish peroxidase (Santa Cruz Biotechnology) for $1 \mathrm{~h}$ at room temperature. Protein signals were visualized using an enhanced chemiluminescence kit (Amersham Biosciences, Piscataway, NJ, USA) and ChemiDocTM Imaging System (Bio-RAD, 17001401).

\subsection{Three-Dimensional (3D) Spheroids Culture and EVs Isolation}

For 3D culture, OOM-SCs and WJ-MSCs were seeded at $2 \times 10^{6}$ cells per well onto F127 (P2443, Sigma)-coated AggreWell 400 ${ }^{\mathrm{TM}}$ plates (STEMCELL Technologies, 34425, Vancouver, BC, Canada) and then incubated overnight for embryonic bodies (EBs) formation. Then, we transferred EBs into a $100 \mathrm{~mm}$ petri dish (SPL, 10090) and cultured them with a 10\% EV-depleted FBS medium. Next, the culture plates were transferred onto an Orbital shaker (ORS) with a sticky mat (INFORS HT Celltron, 69455) and subjected to rotation at $60 \mathrm{rpm}$ for two days. We then collected the media and purified EVs as described above. The characterization of the isolated EVs was performed using NTA as described above. In this experiment, we compared the concentration of 3D culture-derived EVs with monolayer-derived EVs.

\subsection{Senescence-Associated $\beta$-Galactosidase (SA- $\beta$ gal) Assay}

To estimate the impact of OOM-SC-EVs in ameliorating senescence-related changes in the late stage of normal human dermal fibroblasts (NHDFs) (P15-17) (Promocell, C12302, Heidelberg, Germany), we performed SA- $\beta$ gal staining as described previously [52]. In brief, cells were seeded onto 6-well plates and incubated at $37{ }^{\circ} \mathrm{C}$ and $5 \% \mathrm{CO}_{2}$ until reaching $80 \%$ confluence. Next, cells were exposed to $1.5 \times 10^{9}$ particles $/ \mathrm{mL}$ of OOM-SCEVs for $24 \mathrm{~h}$ at $37^{\circ} \mathrm{C}$. Cells were then washed with PBS and fixed with a mixture of $0.2 \%$ glutaraldehyde ( $\mathrm{vol} / \mathrm{vol})$ and $2 \%$ formaldehyde $(\mathrm{vol} / \mathrm{vol})$ that was diluted in PBS buffer for $5 \mathrm{~min}$ at RT, followed by the removal of the fixative solution and washing twice with PBS. Subsequently, we added a freshly prepared SA- $\beta$ gal staining solution to the cells and incubated it overnight at $37^{\circ} \mathrm{C}$ (without $\mathrm{CO}_{2}$ ). We prepared SA- $\beta$ gal staining solution using a mixture of $40 \mathrm{mM}$ citric acid/Na phosphate buffer, $5 \mathrm{mM} \mathrm{K}_{3}\left[\mathrm{Fe}(\mathrm{CN})_{6}\right], 5 \mathrm{mM}$ $\mathrm{K}_{4}\left[\mathrm{Fe}(\mathrm{CN})_{6}\right], 3 \mathrm{H}_{2} \mathrm{O}, 2 \mathrm{mM}$ magnesium chloride, $150 \mathrm{mM}$ sodium chloride, and $1 \mathrm{mg} / \mathrm{mL}$ $\mathrm{X}$-gal dissolved in distilled water. Stained cells were then washed twice with PBS and once with methanol. Finally, cells were dried and kept at room temperature under protection from light until being photographed using phase-contrast microscopy. SA- $\beta$ gal-positive cells showed blue color. 


\subsection{Reactive Oxygen Species (ROS) Generation Measurement}

To measure the modulation of intracellular generation level of ROS after EVs treatment, we measured the changes in the intracellular ROS level using $2^{\prime}, 7^{\prime}$-dichlorodihydrofluorescein diacetate $\left(\mathrm{H}_{2} \mathrm{DCFDA}\right.$, Invitrogen) according to the manufacturer's protocol. In brief, the cells were incubated with $1.5 \times 10^{9}$ particles/mL of OOM-SC-EVs for $24 \mathrm{~h}$ at $37^{\circ} \mathrm{C}$. Following incubation, cells were washed twice with PBS and then incubated with $10 \mu \mathrm{M} \mathrm{H}_{2}$ DCFDA solution for $30 \mathrm{~min}$ at $37^{\circ} \mathrm{C}$ and $5 \% \mathrm{CO}_{2}$ under protection from light by wrapping in aluminum foil. ROS-induced green fluorescent signals were visualized using a fluorescence microscope (Nikon Eclipse TE2000-E). In addition, the fluorescence intensity of the H2DCFDA probe was measured using flow cytometry.

\subsection{Melanin Content Assay}

B16F10 cells were seeded onto 12-well plates at a density of $4 \times 10^{4}$ cells/well and cultured with RPMI medium containing 10\% FBS overnight. Subsequently, $200 \mathrm{nM} \alpha-$ melanocyte-stimulating hormone ( $\alpha$-MSH) (sigma, M4135) and dose-dependent exposure of OOM-SC-EVs $\left(1.5,3,9\right.$, and $15 \times 10^{8}$ particles $\left./ \mathrm{mL}\right)$ or arbutin $(100 \mu \mathrm{M})($ Sigma, A4256) were administered and incubated for $60 \mathrm{~h}$. Further, to measure extracellular melanin, we transferred $100 \mu \mathrm{L}$ of culture medium to a new 96-well plate, and absorbance was detected at $405 \mathrm{~nm}$ wavelength with a Bio-RAD x-MarkTM spectrophotometer. Additionally, for intracellular melanin measurement, each well was washed with PBS and then dissolved with $200 \mu \mathrm{L}$ of $1 \mathrm{~N} \mathrm{NaOH}$ for $1 \mathrm{~h}$ at $80^{\circ} \mathrm{C}$. Absorbance was then measured at $405 \mathrm{~nm}$. The extracellular and intracellular melanin levels were normalized to the total protein concentration.

\subsection{Tyrosinase Activity Assay}

B16F10 cells were cultured at a density of $4 \times 10^{4}$ cells/well onto 12-well plates for $24 \mathrm{~h}$. Subsequently, each well was treated with $200 \mathrm{nM}$ of $\alpha$-MSH and OOM-SC-EVs (1.5, 3, 9 , and $15 \times 10^{8}$ particles $\left./ \mathrm{mL}\right)$ or arbutin $(100 \mu \mathrm{M})$ and then incubated for $48 \mathrm{~h}$. Each well was washed with PBS, and the cells were harvested with PBS and suspended in $50 \mathrm{mM}$ of phosphate buffer ( $\mathrm{pH}$ 6.8) containing $1 \%$ Triton X-100. After vortexing, the mixture was incubated at $80{ }^{\circ} \mathrm{C}$ for $30 \mathrm{~min}$ and then subjected to thawing at room temperature. After centrifugation at $1000 \times g$ for $10 \mathrm{~min}, 40 \mu \mathrm{L}$ of the supernatant and $100 \mu \mathrm{L}$ of $10 \mathrm{mM}$ L-DOPA (Sigma, 333786) were added to a 96-well plate and incubated at $37^{\circ} \mathrm{C}$ for $1 \mathrm{~h}$. Absorbance was then measured at $405 \mathrm{~nm}$ using a Bio-RAD x-MarkTM spectrophotometer. Each absorbance value was normalized to that of total protein.

\subsection{In Vitro Cell Migration (Scratch Assay)}

To evaluate the effect of OOM-SC-EVs on the migration of NHDFs, which were seeded at a density of $5 \times 10^{5}$ cells/well onto 6-well plates and cultured in high-glucose DMEM containing 10\% FBS and 1\% PS until confluency. To stop cell proliferation, $10 \mu \mathrm{g} / \mathrm{mL}$ mitomycin C (M4287, Sigma) was treated for $2 \mathrm{~h}$ at $37^{\circ} \mathrm{C}$, and subsequently, we scratched the cells with a $200-\mu \mathrm{L}$ tip after washing. After treatment with $1.5 \times 10^{9}$ particles $/ \mathrm{mL}$ OOM-SC-EVs or WJ-MSC-EVs, in vitro wound (scratch) closure was examined, and the evaluation of the size of the wound closure (in triplicate) was performed using TScratch software [53].

\subsection{In Vivo Wound Healing Assay}

To analyze the in vivo wound healing capacity, we used six-week-old BALB/c nude female mice (CAnN.Cg-Foxn1nu/CrljOri SPF/VAF Immunodeficient mice), which were purchased from ORIENT BIO Animal Center (Seongnam-si, Korea). The immunodeficient mice (with innate immunity) used in this study are hairless mice, which obviate the difficulties of using haired mice, such as the inflammation or unexpected wounds from the hair removal process, hindering the wound healing process from hair re-growth, and both mice share similar wound healing stages [54]. The in vivo experiment was performed 
following the approval from the Institutional Animal Care and Use Committee (IACUC) at Konkuk University (approval no.: KU20132-1). One week before the experiment, the mice were kept in a well-ventilated room with adjusted temperature and humidity and under a $12 \mathrm{~h}$ light $/ 12 \mathrm{~h}$ dark cycle for appropriate adaptation. The animals were provided with food and water ad libitum. They were divided into two groups as follows: (1) Control wounded group (PBS treated) and (2) OOM-SC-EV-treated group ( $\mathrm{n}=5$ mice in each group). Before creating the in vivo wound, all mice were subjected to anesthesia via the intraperitoneal injection of $60 \mathrm{mg} / \mathrm{kg}$ of alfaxalone (Alfaxan; Careside, Gyeonggi-do, Korea). Mice were anesthetized, and wounds were excised using a sterile biopsy punch (diameter of $8 \mathrm{~mm}$; Kai Industries, Tokyo, Japan) to make two full-thickness skin wounds on the back of each of the animals. The mice were then injected subcutaneously at four points around each wound; only PBS (control group) and $1.5 \times 10^{9}$ particles $/ \mathrm{mL}$ of OOM-SC-EVs were suspended in $30 \mu \mathrm{L}$ PBS. To protect the wounds from external contamination, they were sealed with silicon $(0.5 \mathrm{~mm} \mathrm{~T})$, Tegaderm tape $(1622 \mathrm{~W})$, and bandage (DUPOL). We monitored the progress in wound closure using a digital camera. The size of the wounds was measured with a 30-cm ruler and recorded using a camera in a time-dependent manner. In addition, we measured scar formation at 2 weeks post-wounding. On day 14 after cell injection, the mice were sacrificed, and skin tissues around the wounds were sectioned, fixed using $4 \%$ paraformaldehyde (PFA, Biosesang, Korea), and dehydrated using various concentrations of alcohol, followed by paraffin embedding. Subsequently, the tissues were cut vertically to the wound surface into $4 \mu \mathrm{m}$ thick tissue sections, and the cut tissues were placed on slides that were pre-coated with poly L-lysine $0.1 \% w / v$ (Sigma, St. Louis, MO, USA). For visualization of tissue lesions and regeneration, the sections were subjected to hematoxylin and eosin staining to evaluate the degree of re-epithelization. In addition, Masson's trichrome staining was used to estimate the rate of collagen synthesis. To obtain the tissue images, the slides were scanned using a digital slide scanner (3d-histech, H-1141 Budapest, Öv u. 3., Hungary).

\subsection{Statistical Analysis}

All statistical analyses were performed using GraphPad Prism (version 7). All experiments were performed independently at least in triplicate. Data are expressed as means \pm SD. $p$-values were calculated using one-way ANOVA or RMANOVA and twotailed $t$ test to determine statistical significance. In all figures, the asterisk symbol indicates statistical significance as follows: ${ }^{*} p<0.05 ;{ }^{* *} p<0.01$; ${ }^{* *} p<0.001$; ${ }^{* * *} p<0.0001$, and ns; not significant.

\section{Results}

\subsection{OOM-SCs Characterization}

To prepare OOM-SCs, we obtained muscle fragments from the pretarsal portion of the OOM of healthy patients (both elders and youngsters) who underwent eyelid surgeries. The isolation method for the OOM-derived cells was based on enzymatic digestion using collagenase type II after washing and chopping of the OOM tissues, followed by several centrifugations, and seeding of the obtained single cell onto a $0.2 \%$ gelatin-coated culture plate, as shown in Figure 1A. From patients $(n=16)$ (Supplementary Table S1), we could isolate the pretarsal parts of OOM tissues, which are composed of orbital, preseptal, and pretarsal parts [55] (Figure 1B,C). We also isolated OOFCs using the enzymatic digestion method.

Then, we confirmed the spindle-like morphology and the adherence of OOM-SCs derived from a 74-year-old donor (OOM-SC-74) and the OOFC-74 that derived from the same donor (Figure S1A). We also found a sharp increase in population doubling time in OOFC-74 at P 9, whereas OOM-SC-74 showed an increase in the doubling time at P13 (Figure S1B). OOM-SC-74 showed a marked higher cumulative cell number compared with that shown by OOFC-74 (Figure S1C). 
We compared the population doubling time and cumulative number rate of OOMSCs that isolated from a 5-year-old donor (OOM-SC-5) with that of other MSCs, namely WJ-MSC, AD-MSCs, and USCs. Among the tested MSCs, WJ-MSCs showed the lowest doubling time $(30.53 \mathrm{~h})$ and maintained the highest proliferation $\left(3.8 \times 10^{14}\right)$ until P13. It was followed by OOM-SCs that possess a doubling time of $39.58 \mathrm{~h}$ and showed the secondbest proliferation capacity: $\left(3.3 \times 10^{11}\right)$ up to P13. (Figure 1D,E). ADS-MSCs showed the third-best proliferating MSCs up to P13, whereas USCs maintained the proliferation capacity up to P9 (Figure 1E). The detailed results of cell doubling time and cumulative cell number are described in Table 2.

Table 2. Comparison of WJ-MSCs, AD-MSCs, USCs, and OOM-SCs in the cumulative cell number and doubling time in correlation with the volume of tissue of origin.

\begin{tabular}{ccccc}
\hline & WJ-MSCs & AD-MSCs & USCs & OOM-SCs \\
\hline Volume/Length & $14 \mathrm{~cm}$ & $60 \mathrm{cc}$ & $100 \mathrm{~mL}$ & $2 \mathrm{~cm}$ \\
Cumulative Cell Number & $3.8 \times 10^{14}$ & $2.1 \times 10^{10}$ & $1.0 \times 10^{10}$ & $3.3 \times 10^{11}$ \\
Doubling time & $30.53 \mathrm{~h}$ & $42.34 \mathrm{~h}$ & $44.46 \mathrm{~h}$ & $39.58 \mathrm{~h}$ \\
\hline
\end{tabular}

It is of note that we could not detect any significant difference in the proliferation of OOM-SC-5 or OOM-SC-74. Taken together, OOM-SC-5 showed the best in the cell proliferation kinetics compared with other MSCs except for WJ-MSCs, which showed better proliferation capacity. We, therefore, used WJ-MSCs as a potential control MSCs for our further experiments.

We found that OOM-SC-5 showed high CFU (Figure 2A). We also verified the high expression of the stemness markers, such as Nanog, Sox2, and Rex1, similar to those of WJ-MSCs (Figure 2B). Notably, both the MSCs and fibroblasts share a similar morphology [56-58]; therefore, it is essential to confirm that our cells possess MSC characteristics. The OOM-SC-5 and WJ-MSCs showed apparent expression of integrin subunit $\alpha 6$ (ITGA6), CD146, and Transmembrane 4 L Six Family Member 1 (TM4SF1) genes that are known to be highly expressed in MSCs, although, as expected, NHDFs showed no or weak expression of the genes [59-62] (Figure 2C). Further, we assessed the expression levels of CD markers to confirm the MSC properties of OOM-SC-5, and we found that these cells significantly expressed CD29, CD73, CD105, and CD166 MSC-positive markers but not CD19 and CD45 MSC-negative markers (Figure 2D), strongly indicating that OOM-SC-5 are a type of MSCs. In addition, we compared the expression levels of CD markers of OOM-SCs with other adults MSCs including, WJ-MSCs, AD-MSCs, and USCs using the flow cytometry analysis. As shown in other adults MSCs, OOM-SC-5 positively express CD73, CD90, and CD105, whereas they negatively express CD34 and CD 45 Figure 2E. It is of note that USCs showed the lowest expression of CD 105 compared with other MSCs and OOM-SCs. The flow cytometry data is presented in percentages in a table (Figure 2E. right panel). We also found that OOM-SC-5 have adipogenic, chondrogenic, and osteogenic differentiation capacities, which were measured using Oil red $\mathrm{O}$, Alizarin red S, and Alcian blue staining, respectively (Figure 2F). The OOM-SC-5 showed similar adipogenic and osteogenic differentiation capacities to those of WJ-MSCs and higher differentiation ability than that of USCs (Figure 2F, Table 3). In the case of chondrogenic differentiation, OOMSC-5 showed a similar differentiation capacity to that of USCs (Table 3). Taken together, OOM-SC-5 were confirmed to possess the characteristic features of MSCs, most similarly with WJ-MSCs. 
A

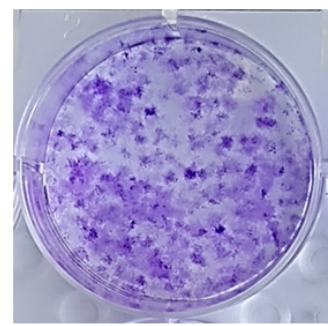

B

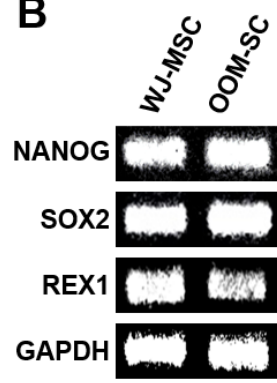

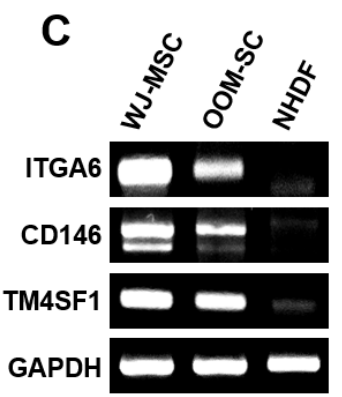

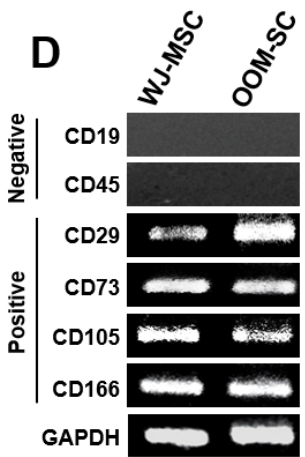

E

Flow cytometry analysis

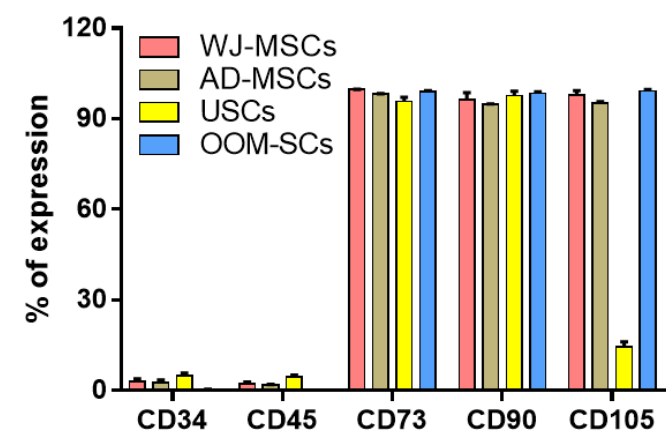

\begin{tabular}{ccccc}
\hline Marker & WJ-MSCs & AD-MSCs & USCs & OOM-SCs \\
\hline CD34 & $3.02 \pm 0.83$ & $2.60 \pm 0.87$ & $4.98 \pm 0.81$ & $0.42 \pm 0.04$ \\
CD45 & $2.20 \pm 0.64$ & $1.70 \pm 0.30$ & $4.51 \pm 0.68$ & $0.03 \pm 0.01$ \\
CD73 & $99.71 \pm 0.09$ & $98.14 \pm 0.20$ & $95.77 \pm 1.36$ & $98.93 \pm 0.46$ \\
CD90 & $96.28 \pm 2.38$ & $94.7 \pm 0.20$ & $97.63 \pm 1.55$ & $98.42 \pm 0.53$ \\
CD105 & $97.81 \pm 1.57$ & $95.14 \pm 0.47$ & $14.41 \pm 1.70$ & $99.30 \pm 0.31$ \\
\hline
\end{tabular}

F
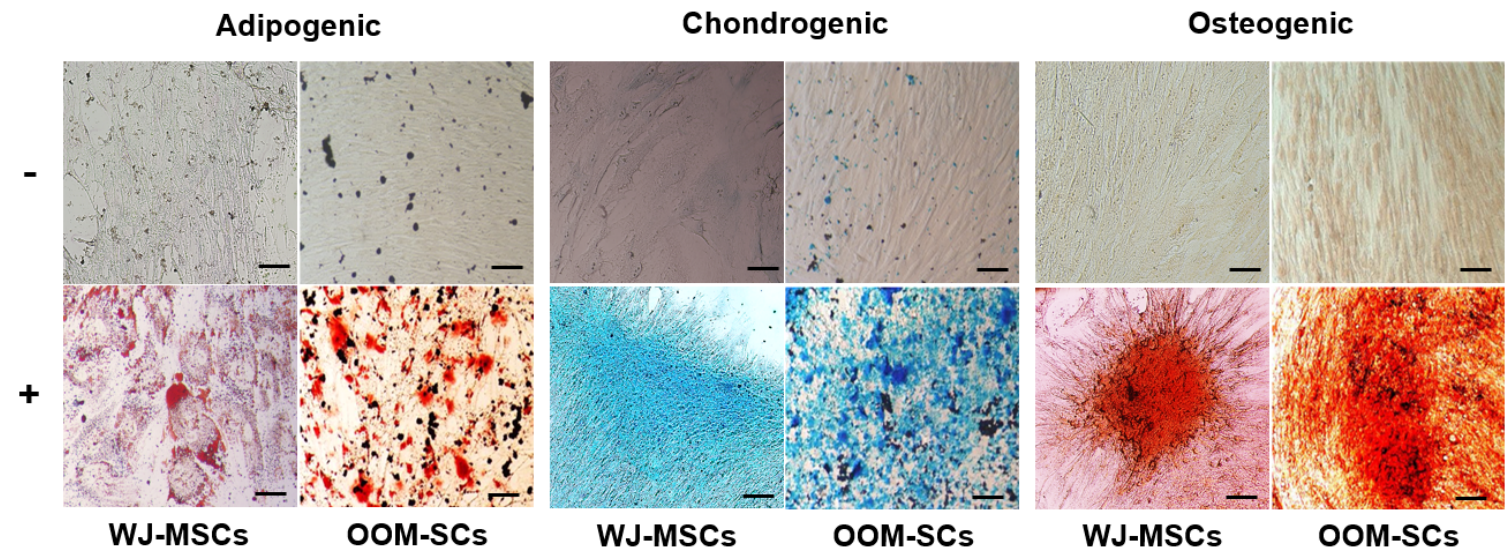

Figure 2. Verification of OOM-SCs Characteristics. (A) Microscopic images depict the CFU of OOM-SCs that were visualized with $0.15 \%$ crystal violet solution after two weeks of culture. Images of the stained colonies were captured using phasecontrast microscopy. (B) RT-PCR results of the expression of the stemness markers Nanog, Sox2, and Rex1 in comparison with those of WJ-MSCs. GAPDH was used as a housekeeping gene. (C) RT-PCR results of specific markers, including ITGA6, CD146, and TM4SF1, distinguish between multipotent MSCs and NHDFs. These genes are only expressed in multipotent MSCs. (D) RT-PCR data for the expression levels of the surface markers of the isolated OOM-SCs compared with those of WJ-MSCs. These markers included the negatively (CD19 and CD45) and positively (CD73, CD105, and CD166) expressed markers. (E) FACS analysis for confirming the expression of the negative markers CD34 and CD45 and positive markers CD73, CD90, and CD105 for OOM-SCs, compared with those of WJ-MSCs. FACS results are summarized in the table (right panel), and all results are presented in percentages. (F) Microscopic images of adipogenic, chondrogenic, and osteogenic differentiation were evaluated by Oil Red, Alcian Blue, and Alizarin Red S staining, respectively. The upper and lower panels represent undifferentiated and differentiated cells, respectively. Scale bar $=200 \mu \mathrm{m}$. 
Table 3. Trilineage differentiation capacity of OOM-SCs compared with those of WJ-MSCs and USCs.

\begin{tabular}{cccc}
\hline & WJ-MSCs & USCs & OOM-SCs \\
\hline Adipogenic & +++ & ++ & +++ \\
Chondrogenic & +++ & ++ & ++ \\
Osteogenic & +++ & ++ & +++ \\
\hline
\end{tabular}

\subsection{OOM-SC-EVs and WJ-MSC-EVS Characterization}

To prepare OOM-SC-EVs and WJ-MSC-EVs, cells were cultured in $10 \%$ exosomedepleted FBS media for $48 \mathrm{~h}$ until reaching $80-90 \%$ confluency. Dead cells and cell debris were removed via differential centrifugation, and the ultrafiltration process, and EVs were collected in a filter device using an Amicon 10-kDa (pore size) regenerated cellulose membrane. The TEM images of the purified EVs revealed the morphology of the purified EVs, which were cup- or sphere-shaped (Figure 3A). We confirmed the expression levels of EV-associated positive markers including the tetraspanin membrane proteins, namely CD9, CD63, and CD81 using immunoblotting (Figure 3B). Moreover, we verified the expression levels of EV-negative markers, such as calnexin and 130-kDa cis-Golgi matrix protein (GM130), which were not detected in the OOM-SC-EVs and WJ-MSC-EVs (Figure 3B).

The EVs size distribution was tracked using a Nanosizer or DLS, and we could not detect any significant variation in the size between OOM-SC-EVs and WJ-MSC-EVs with a size range of 90 to $120 \mathrm{~nm}$ (Figure 3C), while their concentration was determined to be $1.66 \times 10^{10}$ particles $/ \mathrm{mL}$ for OOM-SC-EVs and $1.5 \times 10^{10}$ particles $/ \mathrm{mL}$ for WJ-MSC-EVs, which measured using NTA (Figure 3D). Finally, we confirmed the expression levels of the positive EVs markers using FACS analysis. For OOM-SC-EVs, CD63, and CD81 expression levels were $99.5 \%$ and $99.4 \%$, respectively. In the case of OOM-SC-EVs, the CD63 and CD81 expression levels were $98.7 \%$ and $99.9 \%$, respectively (Figure 3E).

In addition, supplementary Table S2 summarizes the criteria for EVs preparation and characterization according to the recommendations of Minimal information for studies of extracellular vesicles 2018 (MISEV2018) that calibrate the EVs preparation procedure [63].

\subsection{Advanced 3D Culture Approach for Efficient EVs Production}

In this experiment, we pursued an efficient approach for EVs production with a high yield in comparison with the monolayer culture system. For that purpose, we prepared spheroids from OOM-SC-74 and WJ-MSCs using ORS at $60 \mathrm{rpm}$ for two days. Figure 3F shows the spheroids morphology of OOM-SC-74 and WJ-MSCs compared with the monolayer morphology of WJ-MSCs. We purified EVs from the culture supernatant of the cultured spheroids and monolayer, and we measured the number of the particles per cell and the EVs concentration. We could isolate a significantly higher particles number per cell (Figure 3G) and higher concentration (Figure 3H) in the case of 3D culture compared with the monolayer culture.

\subsection{OOM-SC-EV Treatment Modulated ROS Generation and DELAYED Senescence-Related Changes in NHDFs}

We examined the potential of OOM-SC-EVs in delaying senescence-associated changes in NHDFs. The late-stage NHDFs showed a high number of SA- $\beta$ gal-positive, blue-colored cells; however, treatment with OOM-SC-EVs led to a significant decrease in SA- $\beta$ gal positive cells compared with control cells (Figure 4A). We then measured the modulation of ROS generation following OOM-SC-EV treatment and found that high levels of ROS generation in late passage NHDFs were significantly suppressed upon the treatment (Figure 4B). Moreover, we observed that this treatment resulted in a significant increase in the expression levels of antioxidant genes, such as glutathione peroxidase (GPX) 2, GPX3, glutathione S-reductase (GSR), and catalase (Figure 4C). Additionally, OOM-SC-EVexposed cells showed a marked increase in the expression level of extracellular superoxide dismutase (SOD3) (Figure 4C). 
A

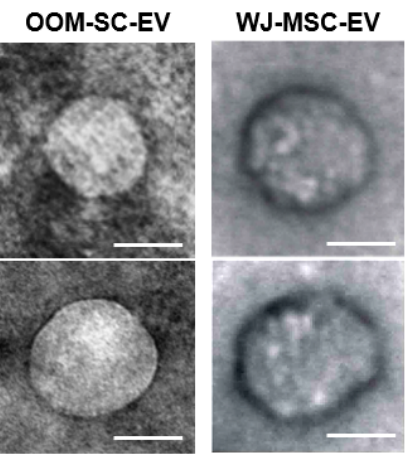

B

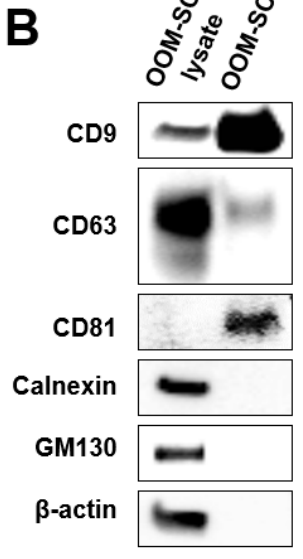


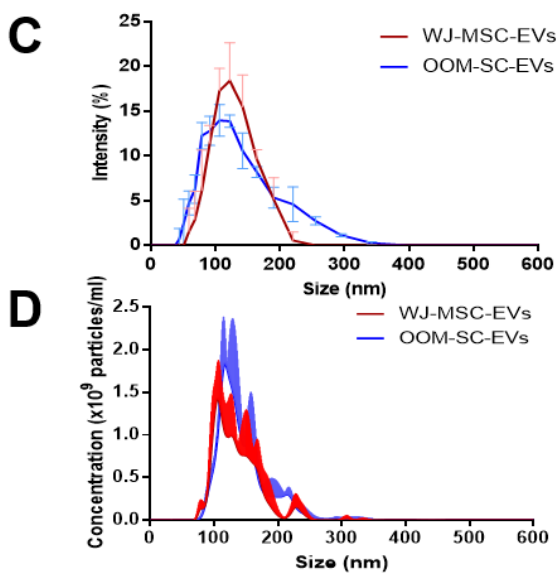

E
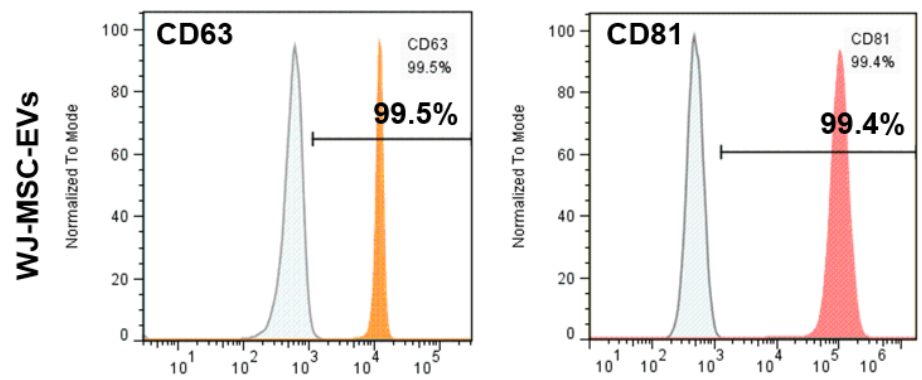

$\mathbf{F}$

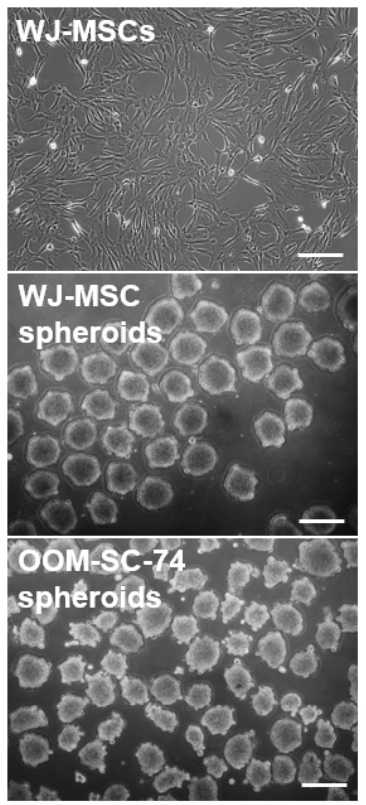

G

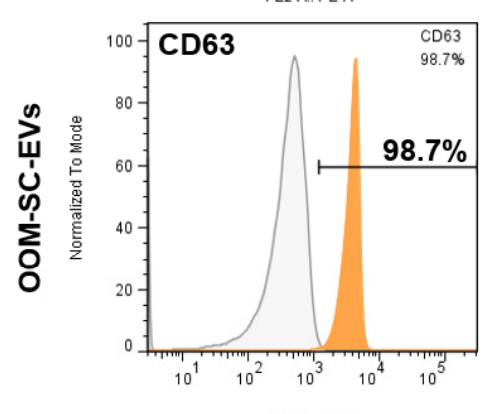

FL2-A: PE-A

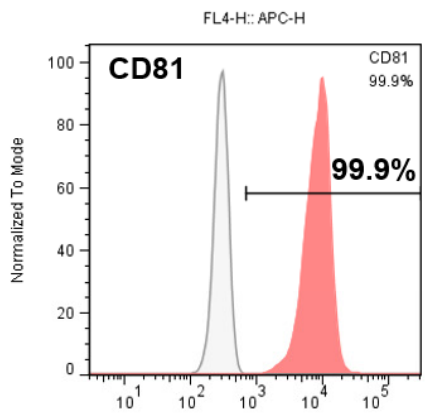

FL4-H:APC-H



H

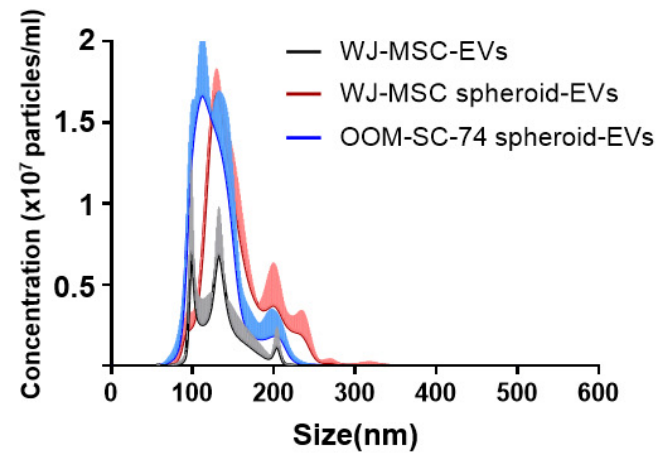

Figure 3. Characterization of OOM-SC-EVs. (A) TEM images of EVs showing cup- or sphere-shaped morphology. TEM analysis was performed at $80 \mathrm{kV}$. Scale bar $=100 \mathrm{~nm}$. (B) Characterization of the expression levels of the EV-associated positive surface markers, including CD9, CD63, CD81, calnexin, and GM130, via immunoblotting. We used $3 \mu \mathrm{g}$ of EVs for the immunoblotting analysis. The protein expression levels of the EV markers were compared with those of the whole cell lysate. (C) Dynamic light scattering analysis of EVs sizes. The average diameter of the purified EVs was of a size range of 90 
to $120 \mathrm{~nm}$. (D) Nanoparticle tracking analyzer NS300 for counting EV numbers. EVs concentrations were $1.66 \times 10^{10}$ particles $/ \mathrm{mL}$ for OOM-SC-EVs and $1.5 \times 10^{10}$ particles/mL for WJ-MSC-EVs. (E) FACS analysis confirmed the expression of EV-associated markers, namely CD63 and CD81. (F) Phase-contrast microscopic pictures of WJ-MSCs monolayer and spheroids of WJ-MSCs and OOM-SCs (OOM-SC-74). For spheroid culture, WJ-MSCs and OOM-SCs were seeded onto F127 -coated AggreWell 400 ${ }^{\mathrm{TM}}$ plates for $24 \mathrm{~h}$ for EB formation. Then, EBs were transferred to the ORS at $60 \mathrm{rpm}$ for two days. EVs were isolated from both spheroids and the monolayer simultaneously. Scale bar $=200 \mu \mathrm{m}$. $(\mathrm{G}, \mathrm{H}) \mathrm{Nanoparticle}$ tracking analyzer NS300 for counting EV numbers in monolayer and spheroids. We detected 1246 particles/cell in WJ-MSCs monolayer, whereas EVs yield from WJ-MSCs and OOM-SCs spheroids were 3984 particles/cell and 4033 particles/cell, respectively. Data shown in Figure $3 G$ are presented as mean \pm SD. Statistical significance was determined using One-way ANOVA: ${ }^{* * *} p<0.0001$, ns; not significant.

A
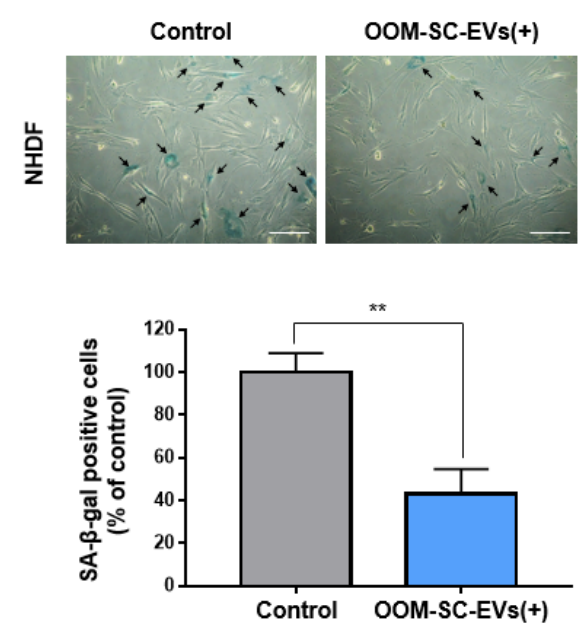

B
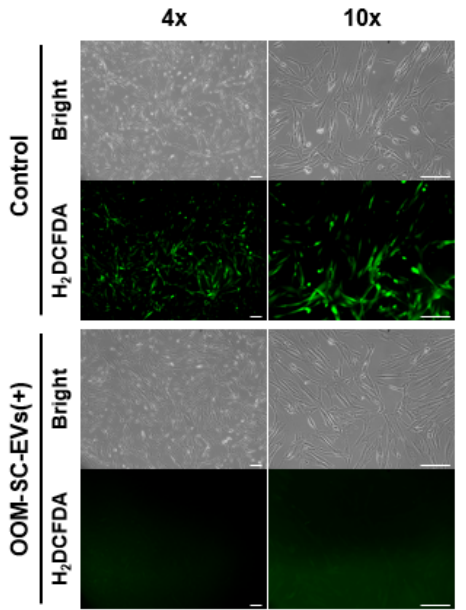
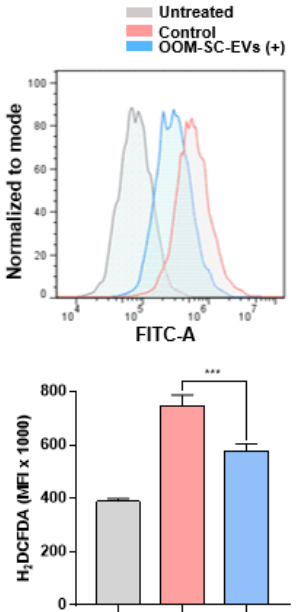
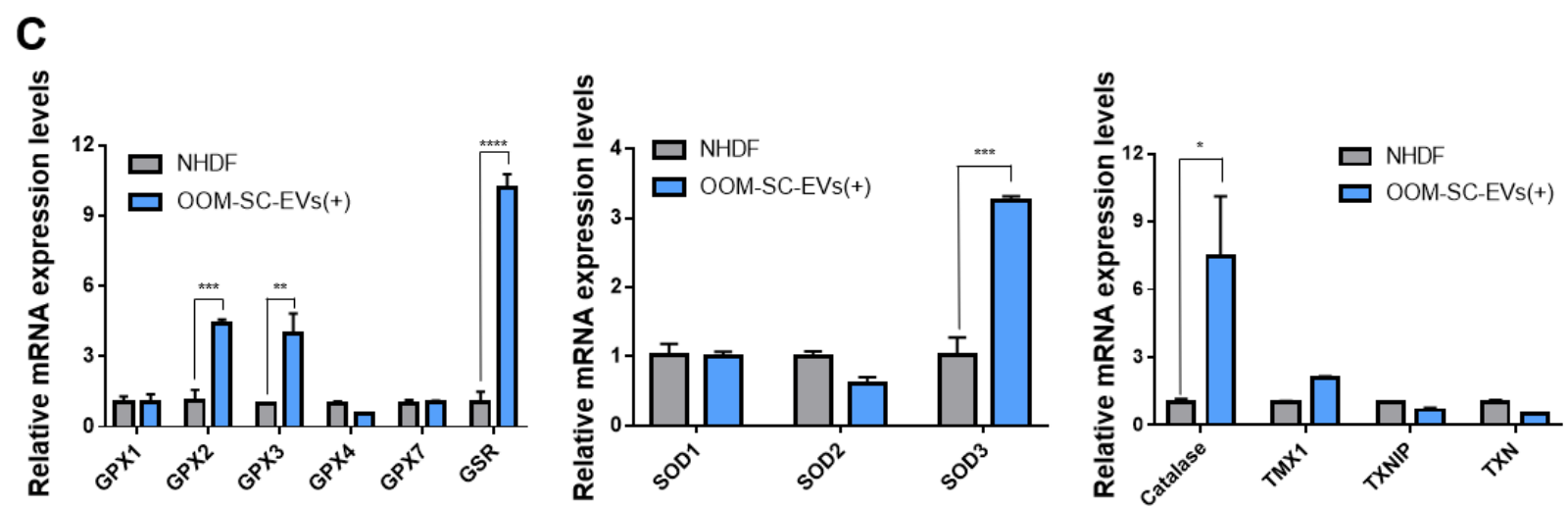

Figure 4. OOM-SC-EVs alleviate senescence-associated changes and modulate ROS generation. (A) SA- $\beta$ gal assay showing a significant reduction of SA- $\beta$ gal-positive cells after OOM-SC-EV treatment. SA- $\beta$ gal-positive cells are stained blue. The lower panel graphical data represents the number of SA- $\beta$ gal-positive cells shown in the upper panel, shown as a percentage of that of the control cells (late passage NHDF). Data are presented as mean \pm SD. Statistical significance was determined using Two-tailed $t$ test: ${ }^{* *} p<0.01$. Scale bar $=200 \mu \mathrm{m}$. (B) Mitigation of ROS generation in OOM-SC-EV-treated late passage NHDF cells. ROS signals were detected via incubation in a $10 \mu \mathrm{M} \mathrm{H} 2 \mathrm{DCFDA}$ solution for $30 \mathrm{~min}$ at $37^{\circ} \mathrm{C}$, followed by observation using a fluorescence microscope. The left panel shows the visualization of ROS green signals using the fluorescent microscope, while the right panels show the FACS-mediated quantitative analysis of ROS generation. The left panel shows the visualization of ROS green signals using the fluorescent microscope, while the right panel shows the FACS-mediated quantitative analysis of ROS generation. Data are presented as mean $\pm \mathrm{SD}$. Statistical significance was determined using One-way ANOVA: ${ }^{* *} p<0.001$. Scale bar $=200 \mu \mathrm{m}$. (C) RT-PCR analysis of the expression levels of antioxidant genes in OOM-SC-EV-treated cells. OOM-SC-EVs significantly increased the expression levels of the antioxidant genes GPX2, GPX3, GSR, SOD3, and catalase. Data are presented as mean $\pm \mathrm{SD}$. Statistical significance was determined using Two-tailed $t$ test: ${ }^{*} p<0.05,{ }^{* *} p<0.01,{ }^{* * *} p<0.001$, and ${ }^{* * * *} p<0.0001$. 


\subsection{OOM-SC-EV Treatment Modulated the Melanin Synthesis of B16F10 Melanoma Cells}

We investigated the effect of OOM-SC-EV treatment on cell viability or melatonin synthesis in B16F10 melanoma cells (Figure 5A). The melanoma cells were seeded onto 12-well plates in RPMI 1640 medium and cultured until confluency. The cells were then cultured in DMEM high glucose media and treated with OOM-SC-EVs. There were no significant changes in cell viability upon treatment with $1.5,3,9$, and $15 \times 10^{8}$ particles $/ \mathrm{mL}$ OOM-SC-EVs, although a slight decrease in cell viability was detected upon treatment with $30 \times 10^{8}$ particles $/ \mathrm{mL}$ OOM-SC-EVs (Figure 5B). Subsequently, we treated the B16F10 melanoma cells with a melanin synthesis activator $(\alpha-\mathrm{MSH}, 200 \mathrm{nM})$, melanin synthesis inhibitor (arbutin, $100 \mu \mathrm{M})$, or OOM-SC-EVs $\left(1.5,3,9\right.$, and $15 \times 10^{8}$ particles $\left./ \mathrm{mL}\right)$ and found that OOM-SC-EV treatment led to an apparent inhibitory activity on $\alpha$-MSH-induced melatonin synthesis in a dose-dependent manner (Figure 5C). Additionally, we measured the intracellular and extracellular melanin contents upon OOM-SC-EV treatment and found that this treatment resulted in significant suppression of both intracellular (cell pellets) and extracellular melanin contents (Figure 5D, E). Further, we evaluated changes in the mRNA expression levels of tyrosine synthesis-related genes, namely microphthalmia-associated transcription factor (MITF), tyrosinase-related protein-1 (TYRP-1), and TYRP-2, and tyrosinase activity upon OOM-SC-EV treatment. Our results showed that although there were no significant changes in the expression of the tyrosine synthesis-related genes (Figure 5F), tyrosinase activity was significantly reduced (Figure 5G). This tyrosinase activity-suppressing effect of OOM-SC-EV treatment was also visually confirmed (Figure 5G lower panel).

\subsection{In Vitro and In Vivo Wound Healing and Anti-Wrinkle Capacities of OOM-SC-EVs}

The wound healing and anti-wrinkle capacities of OOM-SC-EVs were examined. We conducted a cell scratch assay using NHDFs and found that NHDF migration increased upon OOM-SC-EV treatment. OOM-SC-EVs led to a similar NHDFs migration-increasing activity to that of WJ-MSC-EVs (Figure 6A,B). We also measured the effect of OOM-SC-74EVs and OOFC-74-EVs on the in vitro wound closure, in which OOM-SC-74-EVs showed a significant closure of the in vitro wound, especially at $24 \mathrm{~h}$ post scratch (Figure S2). Moreover, we found that OOM-SC-EVs treatment significantly increased the expression levels of the anti-wrinkle-related genes ColA1, monocyte chemoattractant protein-1 (MCP1), MCP-3, chemokine (C-C motif) ligand 5 (CCL-5), and plasminogen activator inhibitor-1 (PAI-1), transforming growth factor- $\beta$ (TGF $\beta$ ) 1 , and TGF $\beta 3$ (Figure $6 \mathrm{C}$ ). It is of note that our data show the increased ratio of TGF $\beta 3$ to TGF $\beta 1$, which is in agreement with a previous report's conclusions on the effect of the increased ratio of TGF $\beta 3$ to TGF $\beta 1$ by MSC derived exosome treatment in efficient in in vivo scarless wound healing [64]. 
A

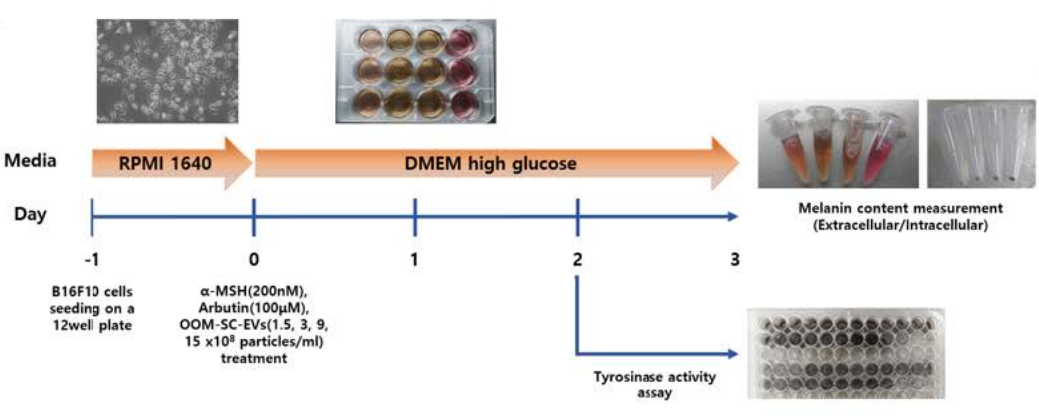

C

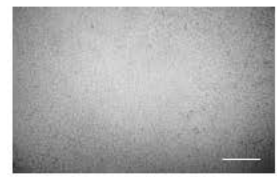

Vehicle

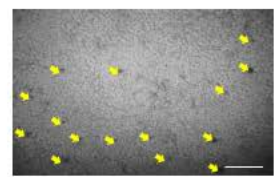

Arbutin

$(100 \mu \mathrm{M})$

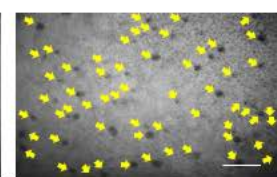

a-MSH (200 nM)

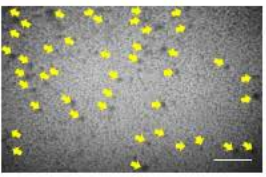

OOM-SC-EVs

$1.5 \times 10^{8}$ particles $/ \mathrm{m}$

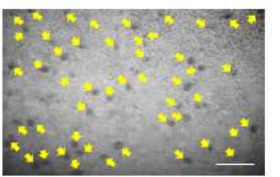

OOM-SC-EVs

$3 \times 10^{8}$ particles $/ \mathrm{ml}$
B

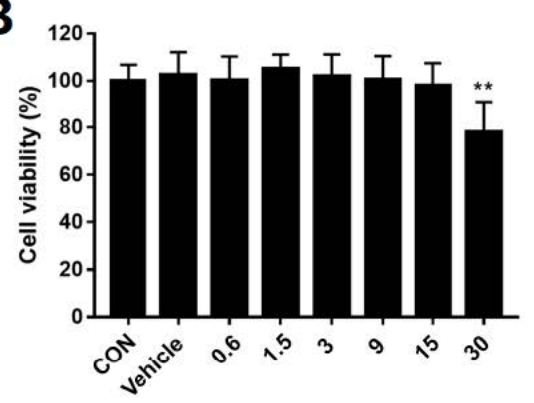

OOM-SC-EVs concentration ( $\times 10^{8}$ particles $/ \mathrm{ml}$ )

D

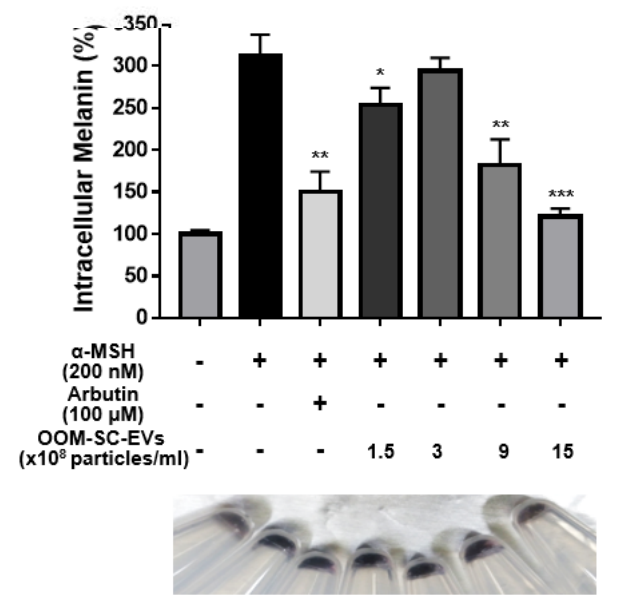

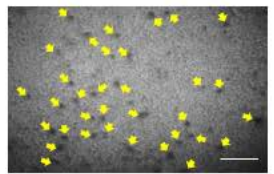

OOM-SC-EVs $9 \times 10^{8}$ particles $/ \mathrm{m}$

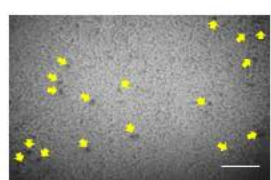

OOM-SC-EVs $1.5 \times 10^{9}$ particles $/ \mathrm{ml}$

a-MSH (200 nM)

E

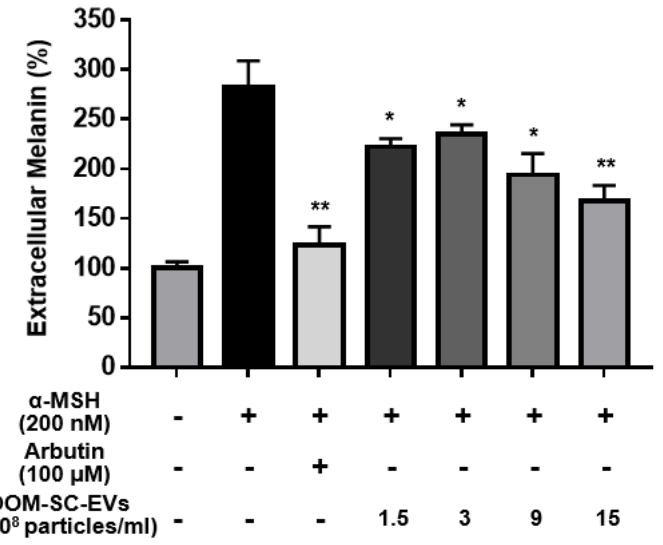

F

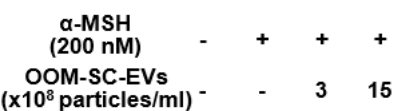

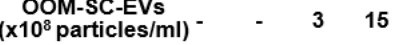

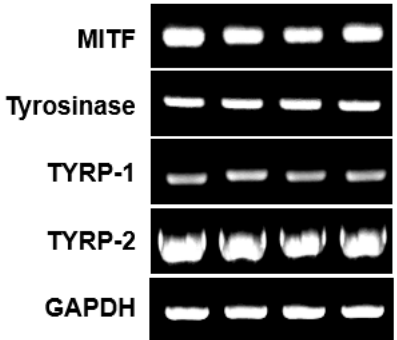

G

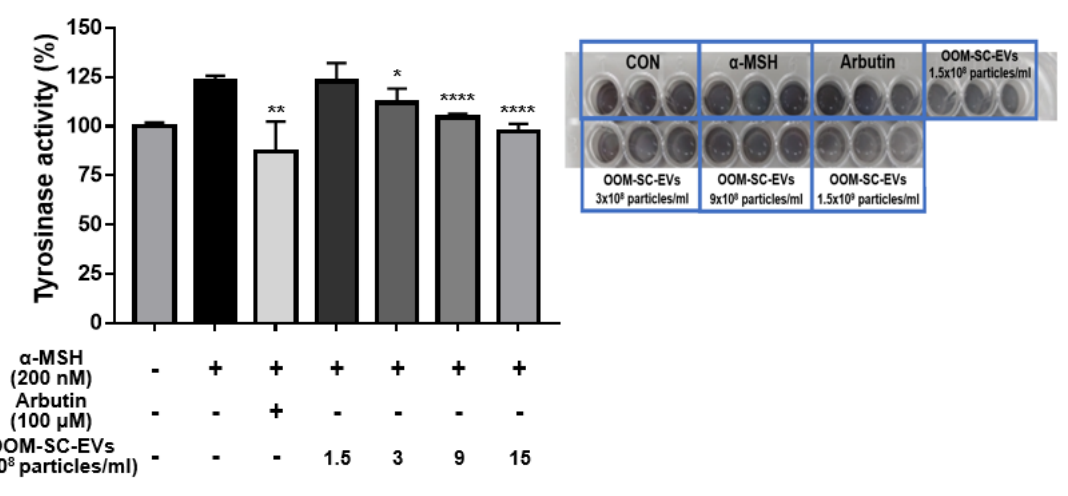

Figure 5. Modulatory effects of OOM-SC-EVs on melanin synthesis and tyrosinase activity. (A) A representative scheme elucidates the experimental schedule for evaluating the effects of OOM-SC-EVs on melanin synthesis and tyrosinase activity. In this experiment, we cultured B16F10 melanoma cells using a growth medium (RPMI 1640). The cells were then exposed 
to OOM-SC-EVs in a dose-dependent manner in combination with arbutin (melanin synthesis inhibitor) and $\alpha$-MSH (melanin synthesis activator) in DMEM high glucose medium. Tyrosine activity and melanin content were measured after OOM-SC-EV and inhibitor treatments on day 2 and day 3, respectively. (B) Effect of concentration-dependent exposure of OOM-SC-EVs on the viability of B16F10 cells. B16F10 cells were plated at $3 \times 10^{3}$ cells/well in a 96-well plate and maintained in serum-free RPMI medium overnight. The cells were then exposed to OOM-SC-EVs in a concentration-dependent manner $\left(0.6,1.5,3,9,15\right.$, and $30 \times 10^{8}$ particles $/ \mathrm{mL}$ ) for $48 \mathrm{~h}$. Subsequently, we added $10 \mu \mathrm{L}$ of CCK-8 solution/well (Dojindo, CK04-05), followed by incubation for $2 \mathrm{~h}$ with protection from light. Absorbance was measured at $450 \mathrm{~nm}$ using a Bio-RAD x-MarkTM spectrophotometer. (C) Microscopic images showing the dose-dependent inhibitory action of OOM-SC-EVs on $\alpha$-MSH-mediated melanosome formation compared with that of the melanin synthesis-suppression chemical arbutin. The formation of melanosomes is indicated by a yellow arrow. OOM-SC-EVs showed a dose-dependent suppression of melanosome formation. Scale bar $=100 \mu \mathrm{m}$. (D) Measurement of intracellular melanin levels after treatment with OOM-SC-EVs. Significant inhibition of melanin synthesis by OOM-SC-EVs was detected at 9 and $15 \times 10^{8} \mathrm{particles} / \mathrm{mL}$, similar to the inhibitory effect of arbutin. The lower panel showing the qualitative inhibitory action of OOM-SC-EVs against melanosome formation was visualized in cells via a change in the color of the cell pellets. (E) Estimation of the effect of OOM-SC-EVs on the suppression of $\alpha$-MSH-mediated induction of extracellular melanin levels compared to that of arbutin. (F) RT-PCR data for measuring changes in the expression levels of melanin synthesis-associated genes, including tyrosine synthesis-related genes, such as MITF, tyrosinase, TYRP-1, and TYRP-2, after treatment with OOM-SC-EVs in combination with $\alpha$-MSH. GAPDH was used as a housekeeping gene. $(\mathrm{G})$ Measurement of tyrosinase activity after treatment with various concentrations of OOM-SC-EVs compared with those after treatment with arbutin and $\alpha$-MSH for $48 \mathrm{~h}$. Subsequently, cells were harvested, permeabilized, frozen and thawed, and centrifuged. For the tyrosine activity assay, the supernatant was mixed with $10 \mathrm{mM}$ L-DOPA in a 96-well plate and incubated for $1 \mathrm{~h}$ at $37^{\circ} \mathrm{C}$. The activity was measured at $405 \mathrm{~nm}$ using a spectrophotometer and represented as a percentage of the control value. The lower panel shows the visual analysis of tyrosinase activity in a 96-well plate. Data shown in Figure 5B,D,E,G are presented as mean \pm SD. Statistical significance was determined in Figure 5B,D,E,G using Two-tailed $t$ test: ${ }^{*} p<0.05,{ }^{* *} p<0.01{ }^{* * *} p<0.001$, and ${ }^{* * *} p<0.0001$.

In addition, we confirmed the in vivo wound healing capacity of OOM-SC-EVs using an animal model. After performing a full-thickness skin wound on the mice back, we injected OOM-SC-EVs subcutaneously in the vicinity of the experimental wound and observed a significant wound healing effect (Figure 6D,E). Moreover, we confirmed the marked re-epithelization of the wound following OOM-SC-EVs treatment using hematoxylin and eosin and Masson's trichrome staining (Figure 6F). 
A

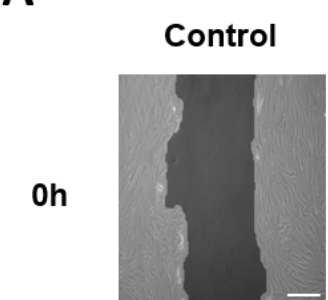

$12 \mathrm{~h}$

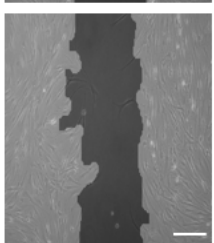

$24 \mathrm{~h}$

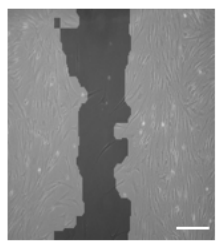

D
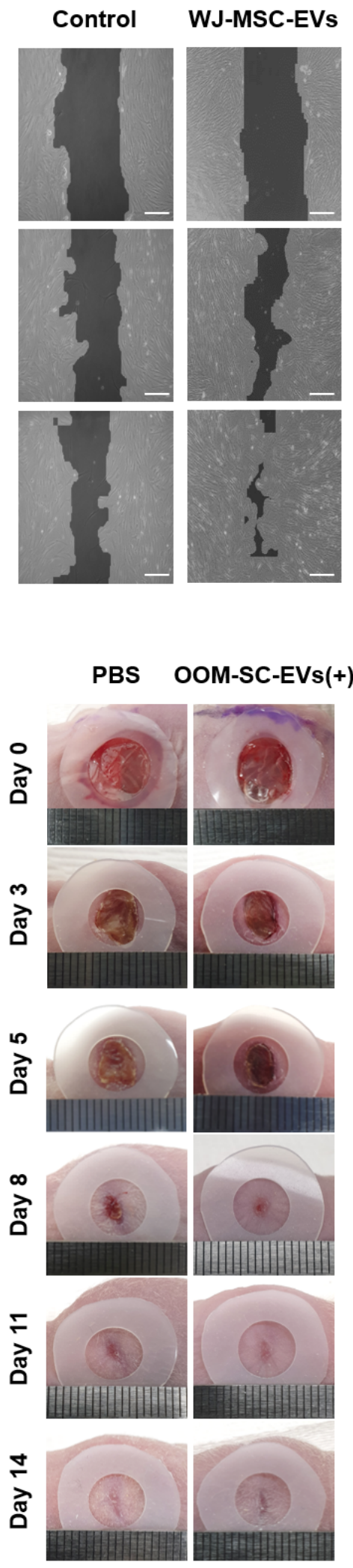

B
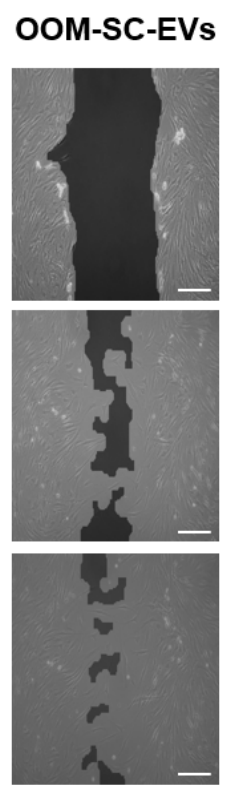

$\mathbf{E}$
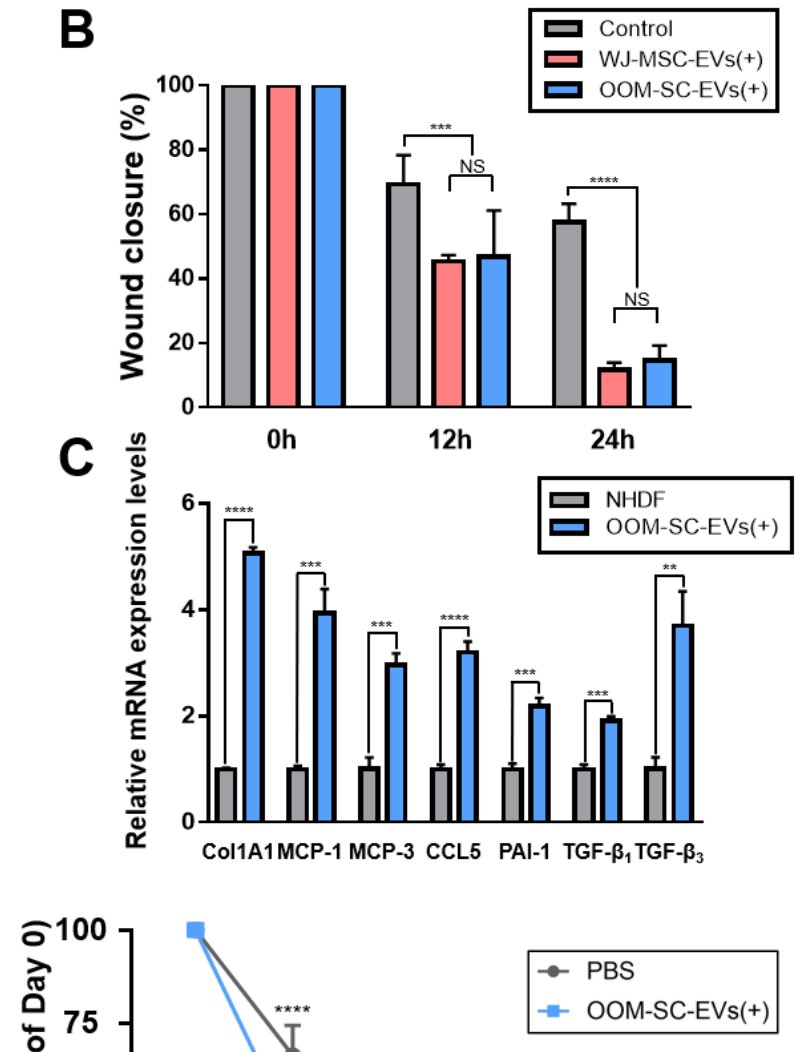

C

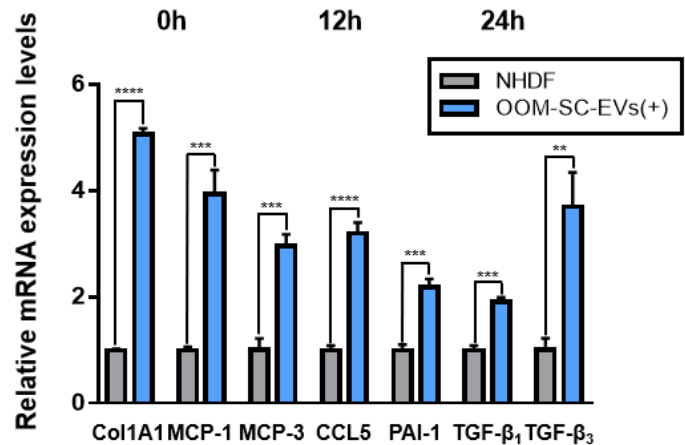

$\mathbf{F}$
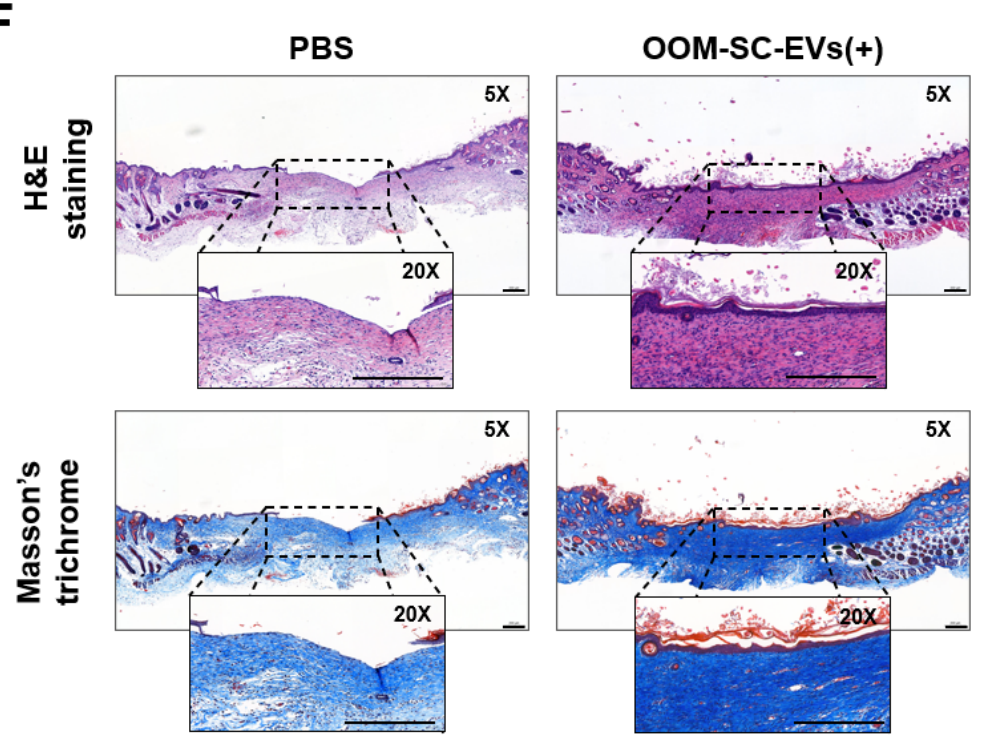

Figure 6. In vitro and in vivo wound healing capacities and the anti-wrinkling activity of the OOM-SC-EVs (A) Effect of OOM-SC-EVs in the closure of in vitro scratches of fully confluent NHDFs tablet $10 . \mu \mathrm{g} / \mathrm{mL}$ mitomycin $\mathrm{C}$ for $2 \mathrm{~h}$ and then scratched with a 200- $\mu \mathrm{L}$ tip. Subsequently, cells were exposed to $1.5 \times 10^{9}$ particles of OOM-SC-EVs or WJ-MSC-EVs in a 
time-dependent manner $(0,12$, and $24 \mathrm{~h})$. Scale bar $=200 \mu \mathrm{m}$. (B) Graphic diagram representing the in vitro scratch assay in Figure $6 \mathrm{~A}$, and the wound closure was evaluated using TScratch software. Data are presented as mean \pm SD. Statistical significance was determined using RMANOVA with post-hoc analysis: ${ }^{* * *} p<0.001$, and ${ }^{* * * *} p<0.0001$, NS; not significant. (C) RT-PCR results showing changes in the expression levels of anti-wrinkle-associated genes. OOM-SC-EV treatment markedly increased the expression levels of collagen synthesis-related genes, namely ColA1, MCP-1, MCP-3, CCL-5, PAI-1, TGF- $\beta 1$, and TGF- $\beta 3$, which are related to high collagen synthesis and the treatment of wrinkles. Data are presented as mean \pm SD. Statistical significance was determined using Two-tailed $t$ test: ${ }^{* *} p<0.01^{* * *} p<0.001$, and ${ }^{* * *} p<0.0001$. (D) In vivo wound healing assay. In this model, two full-thickness skin wounds, on the back of each mouse, were excised via a sterile biopsy punch, followed by the subcutaneous injection of $1.5 \times 10^{9}$ particles $/ \mathrm{mL}$ OOM-SC-EVs diluted in $30 \mu \mathrm{L}$ PBS. Wound closure was monitored every two days until day 14. (E) Graphical data depicting the closure of the wound area as calculated relatively to the original wound area on day 0 after inducing the injury $(n=5)$ and in a time-dependent manner. Data are presented as mean \pm SD. Statistical significance was determined using RMANOVA with post-hoc analysis: ${ }^{* *} p<0.01$, and ${ }^{* * *} p<0.0001$. (F) Hematoxylin and eosin and Masson's trichome staining of the mice skin after sacrifice (on day 14). Two weeks after injection of OOM-SC-EVs into the experimental wound, the skin tissues were fixed with $4 \%$ PFA and then dehydrated using various concentrations of alcohol, followed by paraffin embedding. For the evaluation of regeneration and re-epithelization of the wound after OOM-SC-EV application, the sections were stained with hematoxylin and eosin. Further, Masson's trichrome staining was performed to estimate collagen synthesis rate. Scale bar $=200 \mu \mathrm{m}$.

\section{Discussion}

The goal of our research is to efficiently utilize the waste of human facial tissue from the daily performed ocular surgeries for therapeutic (blepharoplasty and ptosis repair) or cosmetic (double lid crease formation) purposes in both elders and youngsters. Eyelid blepharoplasty is a widespread cosmetic surgery, during which the removed OOM tissues are discarded as medical waste. Compared to muscles in other body sites, the OOM in the eyelids is easily accessible under local anesthesia with little discomfort to the patient, and its removal is far from being associated with loss of function and morbidity for the donor due to its high regenerative capacity. The OOM consists of three anatomic regions, including pretarsal, preseptal, and orbital regions, and each region is suggested to have a different physiological function in the histological microstructure [65]. The pretarsal OOM used in this study contained a high ratio of muscle tissue and a low percentage of fat tissue [65].

In this study, we isolated OOM-SCs from the pretarsal OOMs using the enzymatic digestion method. The OOM-SCs successfully adhered to the culture plate and showed a spindle-like morphology, high clonogenic proliferative behavior, and high stemness and self-renewal capacities. Generally, MSCs have various unique features, including trilineage differentiation potential, stemness, and self-renewal capacities [66]. Similarly, compared with MSCs including WJ-MSCs, AD-MSCs, and USCs, the OOM-SCs showed expression profiles of MSC surface markers and trilineage differentiation potential. Moreover, we confirmed the high expression levels of ITGA6, CD146, and TM4SF1, which are specifically expressed in multipotent MSCs but not in fibroblasts.

The therapeutic potential of MSC-derived EVs has been widely reported [67-72]. EVs, which are secreted by most cells, are lipid vesicles with small membranes with diameters of 30-120 nm [73,74]. Stem cell-derived EVs have been reported to contain transcription factors that are secreted by stem cells, which are responsible for maintaining stem cell properties, as well as secreted signaling molecules, such as WNTs, TGF- $\beta$, and $\beta$-catenin, implicated in EV-mediated therapeutic actions [75-77]. EVs can also convey RNAs, including mRNAs, miRNAs, and lncRNAs, which represent their cells of origin [78-84]. Interestingly, EVs possess the capacity to transfer specific proteins and genetic materials to the recipient cells and, also, EV membranes can be engineered using organ-specific therapeutic proteins or drugs for treating the incurable disease of target organs [85-90]. Moreover, the application of EVs obviates the biosafety issues incurred by the direct application of whole stem cells, including tumorigenicity and immunogenic reactions [91,92]. In the field of ophthalmology, the capacity of EVs to treat immune-related eye diseases, 
retinal inflammation, and retinal ischemia and their application as biomarkers for ocular diseases have been reported [93-97]. The in vivo corneal wound healing activity of MSC-derived exosomes has also been demonstrated [98]. Here, we could effectively isolate and characterize OOM-SC-EVs and reveal their high therapeutic effects on melanogenesis suppression, the anti-wrinkle process, and wound healing. According to the guidelines determined by MISEV2018 for EVs nomenclature, the term EVs can be applied to particles that are naturally released from cells and are characterized by their inability to replicate, are surrounded by a lipid bilayer, and lack any functional nucleus [63]. According to the size, EVs could be classified into small EVs (less than $100 \mathrm{~nm}$ or $200 \mathrm{~nm}$ ) and large or medium EVs (more than $200 \mathrm{~nm}$ ) [63]. In our study, we carried out differential centrifugation, ultrafiltration, and ultracentrifugation to get rid of debris, dead cells, macrovesicles, and most of the soluble proteins. We ultimately obtained small EVs of 90-120 nm.

Interestingly, OOM-SC-EVs led to marked suppression of enhanced ROS generation in the late-passaged (aged) NHDFs. Moreover, they increased the expression levels of antioxidant genes, namely catalase, GPX2, GPX3, GSR, and SOD3 in aged NHDFs. Our data also showed the capacity of OOM-SC-EVs in the in vitro and in vivo wound closure in NHDFs and mice, respectively. This result is consistent with a previous report that umbilical cord MSC-derived EVs showed potent capacities for enhancing wound healing and skin regeneration $[39,99]$. In addition, OOM-SC-EVs markedly enhanced the expression levels of collagen synthesis-related genes, namely ColA1, MCP-1, MCP-3, CCL-5, PAI-1, TGF $\beta 1$, and TGF $\beta 3$. Previous reports have demonstrated the capacities of stem cell-derived exosomes in the alleviation of skin aging change [100], enhancement of collagen synthesis, angiogenesis, and scar healing $[101,102]$. Additionally, EVs have been previously implicated in ROS modulation [103]. To our knowledge, this is the first study revealing the roles of OOM-SCEVs in the improvement of wound healing in vitro and in vivo and in the significant delay in skin aging by promoting the expression levels of collagen synthesis-related genes. We hypothesized that OOM-SC-EV-induced upregulation of collagen synthesis genes may be one of the mechanisms that mediate efficient wound healing. Further studies are required to confirm the crosslink between OOM-SC-EVs and collagen synthesis and to verify OOMSC-EV-related ROS modulation in crosslinks with their therapeutic activities. In addition, the role of OOM-SC-EVs in modulating the immune and inflammatory responses during the wound healing process needs in-depth investigations.

Based on our findings, we can postulate the uptake of OOM-SC-EVs into the epidermis and dermis, followed by the interaction of OOM-SC-EVs with fibroblasts. For clinical or esthetic applications, this effect can emulate the application of microneedles, which are microscopic applicators used to deliver vaccines or other drugs across various barriers, while the transdermal application is the most popular use of microneedles. Microneedles may help overcome poor skin penetration of OOM-SC-EVs, and several novel exciting microneedle concepts may be of great help for the intradermal delivery of OOM-SC-EVs in the future [104].

Melanin possesses a protective function against the harmful effects of ultraviolet (UV) light. However, excess melanin synthesis can result in unfavorable skin disorders, such as spots, freckles, skin hyperpigmentation, and melisma [105,106]. Therefore, inhibition of melanin synthesis has garnered attention in the fields of dermatology and cosmetics. In our study, we showed that OOM-SC-EVs treatment significantly suppressed melanin synthesis in B16F10 cells. Although OOM-SC-EVs treatment did not significantly change the expression levels of melanogenesis-related genes, such as MITF, tyrosinase, TYRP-1, and TYRP-2, it resulted in the significant inhibition of tyrosinase activity. We hypothesized that there is another mechanism associated with OOM-SC-EV-mediated inhibition of melanin synthesis. For instance, previous reports have demonstrated the implication of high ROS generation and depletion of antioxidant factors in the overproduction of melanin [107]. Moreover, several reports have revealed the application of antioxidant agents for the treatment of high melanin-mediated hyperpigmentation [108,109]. Here, we demonstrated the antioxidant activity of OOM-SC-EVs, and therefore, we could postulate 
the role of OOM-SC-EV-related antioxidant activity in melanogenesis inhibition, which needs further investigation.

We sought to improve the yield of OOM-SC-EVs for large scale production in the future, and so we tried to culture OOM-SCs using the 3D platform using the ORS, and we found a marked increase in the EVs yield upon using the 3D platform compared with using 2D culture system (Figure 3). We are planning to perform an in-depth investigation on the mechanism implicated in the high yield of EVs during the 3D culture system compared to the monolayer system in a future study. We also will verify the capacity of the 3Dderived EVs in the disease model. It is noteworthy that we could not detect any significant difference in terms of cell number, EVs yield, and functions between cells obtained from youngsters and elders. Notably, the 3D platform showed a significantly better EVs yield than that shown in the 2D platform (Figure 3). Therefore, in our future study, we planned to devise a detailed efficient protocol for OOM-SC-EVs production using the 3D culture system. Our study affords a good source for stem cell yield that ultimately produces high-quality EVs, which possess various applications including antioxidant, anti-wrinkle, anti-senescence, whitening effect, and skin regenerative capacity (Figure 1A).

\section{Conclusions}

In conclusion, we were able to efficiently isolate and culture OOM-SCs from the human facial tissues (from youngsters and elders) that were discarded after eyelid blepharoplasty or epiblepharon surgeries. Stem cell properties of OOM-SCs were compared with human adult MSCs (WJ-MSCs, AD-MSCs, and USCs), and possible therapeutic applications of OOM-SC-EVs were verified. Our findings provide new insights into various possible therapeutic and esthetic applications of OOM-SC-EVs, including wound healing, modulation of collagen synthesis-related genes, whitening effect, anti-senescence activity, inhibition of tyrosinase activity, and anti-wrinkling activity. Importantly, we exploited the waste human facial tissues from the daily performed ocular surgeries for therapeutic (blepharoplasty and ptosis repair) or cosmetic (double lid crease formation) purposes in both elders and youngsters. Notably, the 3D platform showed a significantly better EVs yield than that shown in the 2D platform. Our study provides promising therapeutic and esthetic applications of OOM-SC-EVs, which can be competently isolated from the waste human facial tissues.

Supplementary Materials: The following are available online at https:/ /www.mdpi.com/article/10 .3390/antiox10081292/s1, Table S1: List of human orbicular oculi muscle and fat tissue samples, Table S2: Checklist of EV isolation and characterization method, Figure S1: Morphology and proliferation kinetics of OOM-SC-74 and OOFC-74, Figure S2: In vitro wound healing assay of OOM-SC-74-EVs and OOFC-74-EVs.

Author Contributions: Conceptualization, S.-G.C., H.J.S., K.M.L. and A.A.D.; methodology, S.-G.C., H.J.S., K.M.L., Y.C., Y.L., J.A. and S.L.; Founding acquisition, S.-G.C.; Investigation, Validation, Formal analysis, Supervision, Writing—original draft, Writing—-Review and Editing, S.-G.C., H.J.S., K.M.L., A.A.D. and M.G.; Visualization, Investigation, Formal analysis, B.V., and H.J.K.; Animal Surgeries, K.M.L., A.A.D., Y.C., Y.L., J.A., S.L. and H.J.S. All authors have read and agreed to the published version of the manuscript.

Funding: The following research grants are acknowledged: National Research Foundation (NRF) funded by the Korean government (Ministry of Education, Science, and Technology) (grant numbers 2019M3A9H1030682 and 2015R1A5A1009701) and by Konkuk University Researcher Fund in 2019.

Institutional Review Board Statement: The protocols used in this study were approved by the ethics committees of Konkuk University Medical Center (KUMC 2019-05-043), Konkuk University (7001355-201705-BR-181 and 7001355-201507-BR-072), and IACUC at Konkuk University (KU20132) and conformed to the principles outlined in the Declaration of Helsinki.

Informed Consent Statement: Not applicable. 
Data Availability Statement: The data are presented within the paper. Additional raw data are available on request from the corresponding author.

Conflicts of Interest: The authors declare no conflict of interest.

\section{References}

1. Scuderi, N.; Rubino, C. Island chondro-mucosal flap and skin graft: A new technique in eyelid reconstruction. Br. J. Plast. Surg. 1994, 47, 57-59. [CrossRef]

2. Zhou, G. Clinical Experience with Orbicularis Oculi Myocutaneous Flaps in the Temporal Area. Plast. Reconstr. Surg. 2003, 112, 1862. [CrossRef]

3. Yoshimura, Y.; Nakajima, T.; Yoneda, K. Reconstruction of the entire upper eyelid area with a subcutaneous pedicle flap based on the orbicularis oculi muscle. Plast. Reconstr. Surg. 1991, 88, 136-139. [CrossRef] [PubMed]

4. Kostakoğlu, N.; Özcan, G. Orbicularis oculi myocutaneous flap in reconstruction of postburn lower eyelid ectropion. Burns 1999, 25, 553-557. [CrossRef]

5. Mawrie, D.; Kumar, A.; Magdalene, D.; Bhattacharyya, J.; Jaganathan, B.G. Mesenchymal stem cells from human extra ocular muscle harbor neuroectodermal differentiation potential. PloS ONE 2016, 11, e0156697. [CrossRef] [PubMed]

6. Polisetty, N.; Fatima, A.; Madhira, S.L.; Sangwan, V.S.; Vemuganti, G.K. Mesenchymal cells from limbal stroma of human eye. Mol. Vis. 2008, 14, 431.

7. Formicola, L.; Marazzi, G.; Sassoon, D.A. The extraocular muscle stem cell niche is resistant to ageing and disease. Front. Aging Neurosci. 2014, 6, 328. [CrossRef]

8. Pacheco-Pinedo, E.C.; Budak, M.T.; Zeiger, U.; Jørgensen, L.H.; Bogdanovich, S.; Schrøder, H.D.; Rubinstein, N.A.; Khurana, T.S. Transcriptional and functional differences in stem cell populations isolated from extraocular and limb muscles. Physiol. Genom. 2009, 37, 35-42. [CrossRef]

9. Yamanaka, Y.; Takenaka, N.; Sakurai, H.; Ueno, M.; Kinoshita, S.; Sotozono, C.; Sato, T. Human Skeletal Muscle Cells Derived from the Orbicularis Oculi Have Regenerative Capacity for Duchenne Muscular Dystrophy. Int. J. Mol. Sci. 2019, $20,3456$. [CrossRef]

10. Liu, G.; Liao, C.; Chen, X.; Xu, Y.; Tan, J.; Han, F.; Ye, X. Identification and Characterization of Skeletal Muscle Stem Cells from Human Orbicularis Oculi Muscle. Tissue Eng. Part C Methods 2018, 24, 486-493. [CrossRef]

11. Yáñez-Mó, M.; Siljander, P.R.-M.; Andreu, Z.; Bedina Zavec, A.; Borràs, F.E.; Buzas, E.I.; Buzas, K.; Casal, E.; Cappello, F.; Carvalho, J. Biological properties of extracellular vesicles and their physiological functions. J. Extracell. Vesicles 2015, 4, 27066. [CrossRef] [PubMed]

12. Valadi, H.; Ekström, K.; Bossios, A.; Sjöstrand, M.; Lee, J.J.; Lötvall, J.O. Exosome-mediated transfer of mRNAs and microRNAs is a novel mechanism of genetic exchange between cells. Nat. Cell Biol. 2007, 9, 654-659. [CrossRef]

13. Zhang, Y.; Liu, Y.; Liu, H.; Tang, W.H. Exosomes: Biogenesis, biologic function and clinical potential. Cell Biosci. 2019, 9, 1-18. [CrossRef]

14. Gowen, A.; Shahjin, F.; Chand, S.; Odegaard, K.E.; Yelamanchili, S.V. Mesenchymal stem cell-derived extracellular vesicles: Challenges in clinical applications. Front. Cell Dev. Biol. 2020, 8, 149. [CrossRef] [PubMed]

15. Li, C.-J.; Fang, Q.-H.; Liu, M.-L.; Lin, J.-N. Current understanding of the role of Adipose-derived Extracellular Vesicles in Metabolic Homeostasis and Diseases: Communication from the distance between cells/tissues. Theranostics 2020, 10, 7422. [CrossRef] [PubMed]

16. Rodrigues, M.; Fan, J.; Lyon, C.; Wan, M.; Hu, Y. Role of extracellular vesicles in viral and bacterial infections: Pathogenesis, diagnostics, and therapeutics. Theranostics 2018, 8, 2709. [CrossRef]

17. Gurunathan, S.; Kang, M.-H.; Kim, J.-H. A comprehensive review on factors influences biogenesis, functions, therapeutic and clinical implications of exosomes. Int. J. Nanomed. 2021, 16, 1281. [CrossRef] [PubMed]

18. Nassar, W.; El-Ansary, M.; Sabry, D.; Mostafa, M.A.; Fayad, T.; Kotb, E.; Temraz, M.; Saad, A.-N.; Essa, W.; Adel, H. Umbilical cord mesenchymal stem cells derived extracellular vesicles can safely ameliorate the progression of chronic kidney diseases. Biomater. Res. 2016, 20,1-11. [CrossRef] [PubMed]

19. Kordelas, L.; Rebmann, V.; Ludwig, A.; Radtke, S.; Ruesing, J.; Doeppner, T.; Epple, M.; Horn, P.; Beelen, D.; Giebel, B. MSCderived exosomes: A novel tool to treat therapy-refractory graft-versus-host disease. Leukemia 2014, 28, 970-973. [CrossRef] [PubMed]

20. Sun, Y.; Shi, H.; Yin, S.; Ji, C.; Zhang, X.; Zhang, B.; Wu, P.; Shi, Y.; Mao, F.; Yan, Y. Human mesenchymal stem cell derived exosomes alleviate type 2 diabetes mellitus by reversing peripheral insulin resistance and relieving $\beta$-cell destruction. ACS Nano 2018, 12, 7613-7628. [CrossRef]

21. Zhao, M.; Shi, J.; Cai, W.; Liu, K.; Shen, K.; Li, Z.; Wang, Y.; Hu, D. Advances on Graphene-Based Nanomaterials and Mesenchymal Stem Cell-Derived Exosomes Applied in Cutaneous Wound Healing. Int. J. Nanomed. 2021, 16, 2647. [CrossRef] [PubMed]

22. Han, C.; Sun, X.; Liu, L.; Jiang, H.; Shen, Y.; Xu, X.; Li, J.; Zhang, G.; Huang, J.; Lin, Z. Exosomes and their therapeutic potentials of stem cells. Stem Cells Int. 2016, 2016, 7653489. [CrossRef]

23. Teixeira, F.G.; Carvalho, M.M.; Sousa, N.; Salgado, A.J. Mesenchymal stem cells secretome: A new paradigm for central nervous system regeneration? Cell. Mol. Life Sci. 2013, 70, 3871-3882. [CrossRef] [PubMed] 
24. Keshtkar, S.; Azarpira, N.; Ghahremani, M.H. Mesenchymal stem cell-derived extracellular vesicles: Novel frontiers in regenerative medicine. Stem Cell Res. Ther. 2018, 9, 1-9. [CrossRef] [PubMed]

25. Yang, J.; Chen, Z.; Pan, D.; Li, H.; Shen, J. Umbilical cord-derived mesenchymal stem cell-derived exosomes combined pluronic F127 hydrogel promote chronic diabetic wound healing and complete skin regeneration. Int. J. Nanomed. 2020, 15, 5911. [CrossRef] [PubMed]

26. Basu, J.; Ludlow, J.W. Exosomes for repair, regeneration and rejuvenation. Expert Opin. Biol. Ther. 2016, 16, 489-506. [CrossRef]

27. Phinney, D.G.; Pittenger, M.F. Concise review: MSC-derived exosomes for cell-free therapy. Stem Cells 2017, 35, 851-858. [CrossRef]

28. Goodarzi, P.; Larijani, B.; Alavi-Moghadam, S.; Tayanloo-Beik, A.; Mohamadi-Jahani, F.; Ranjbaran, N.; Payab, M.; Falahzadeh, K.; Mousavi, M.; Arjmand, B. Mesenchymal stem cells-derived exosomes for wound regeneration. Cell Biol. Transl. Med. 2018, 4 119-131.

29. Zhao, B.; Zhang, Y.; Han, S.; Zhang, W.; Zhou, Q.; Guan, H.; Liu, J.; Shi, J.; Su, L.; Hu, D. Exosomes derived from human amniotic epithelial cells accelerate wound healing and inhibit scar formation. J. Mol. Histol. 2017, 48, 121-132. [CrossRef]

30. Hu, P.; Yang, Q.; Wang, Q.; Shi, C.; Wang, D.; Armato, U.; Prà, I.D.; Chiarini, A. Mesenchymal stromal cells-exosomes: A promising cell-free therapeutic tool for wound healing and cutaneous regeneration. Burn. Trauma 2019, 7. [CrossRef]

31. An, T.; Chen, Y.; Tu, Y.; Lin, P. Mesenchymal stromal cell-derived extracellular vesicles in the treatment of diabetic foot ulcers: Application and challenges. Stem Cell Rev. Rep. 2021, 17, 369-378. [CrossRef] [PubMed]

32. Yu, M.; Liu, W.; Li, J.; Lu, J.; Lu, H.; Jia, W.; Liu, F. Exosomes derived from atorvastatin-pretreated MSC accelerate diabetic wound repair by enhancing angiogenesis via AKT/eNOS pathway. Stem Cell Res. Ther. 2020, 11, 1-17. [CrossRef] [PubMed]

33. Lai, P.; Chen, X.; Guo, L.; Wang, Y.; Liu, X.; Liu, Y.; Zhou, T.; Huang, T.; Geng, S.; Luo, C. A potent immunomodulatory role of exosomes derived from mesenchymal stromal cells in preventing cGVHD. J. Hematol. Oncol. 2018, 11, 1-15. [CrossRef]

34. Quiñones-Vico, M.I.; Sanabria-de la Torre, R.; Sánchez-Díaz, M.; Sierra-Sánchez, Á.; Montero-Vílchez, T.; Fernández-González, A.; Arias-Santiago, S. The Role of Exosomes Derived From Mesenchymal Stromal Cells in Dermatology. Front. Cell Dev. Biol. 2021, 9 , 647012. [CrossRef]

35. Théry, C.; Zitvogel, L.; Amigorena, S. Exosomes: Composition, biogenesis and function. Nat. Rev. Immunol. 2002, 2, 569-579. [CrossRef]

36. Colombo, M.; Raposo, G.; Théry, C. Biogenesis, secretion, and intercellular interactions of exosomes and other extracellular vesicles. Annu. Rev. Cell Dev. Biol. 2014, 30, 255-289. [CrossRef]

37. György, B.; Hung, M.E.; Breakefield, X.O.; Leonard, J.N. Therapeutic applications of extracellular vesicles: Clinical promise and open questions. Annu. Rev. Pharmacol. Toxicol. 2015, 55, 439-464. [CrossRef]

38. Henriques-Antunes, H.; Cardoso, R.M.; Zonari, A.; Correia, J.; Leal, E.C.; Jimenez-Balsa, A.; Lino, M.M.; Barradas, A.; Kostic, I.; Gomes, C. The kinetics of small extracellular vesicle delivery impacts skin tissue regeneration. ACS Nano 2019, 13, 8694-8707. [CrossRef] [PubMed]

39. Zhang, B.; Wang, M.; Gong, A.; Zhang, X.; Wu, X.; Zhu, Y.; Shi, H.; Wu, L.; Zhu, W.; Qian, H. HucMSC-exosome mediated-Wnt4 signaling is required for cutaneous wound healing. Stem Cells 2015, 33, 2158-2168. [CrossRef]

40. Sicco, C.L.; Reverberi, D.; Balbi, C.; Ulivi, V.; Principi, E.; Pascucci, L.; Becherini, P.; Bosco, M.C.; Varesio, L.; Franzin, C. Mesenchymal stem cell-derived extracellular vesicles as mediators of anti-inflammatory effects: Endorsement of macrophage polarization. Stem Cells Transl. Med. 2017, 6, 1018-1028. [CrossRef] [PubMed]

41. Bagchi, D.; Das, A.; Roy, S. Wound Healing, Tissue Repair and Regeneration in Diabetes; Academic Press: Cambridge, MA, USA, 2020.

42. Campos, A.M.; Maciel, E.; Moreira, A.S.; Sousa, B.; Melo, T.; Domingues, P.; Curado, L.; Antunes, B.; Domingues, M.R.M.; Santos, F. Lipidomics of Mesenchymal Stromal Cells: Understanding the Adaptation of Phospholipid Profile in Response to Pro-Inflammatory Cytokines. J. Cell. Physiol. 2016, 231, 1024-1032. [CrossRef]

43. Bjørge, I.; Kim, S.; Mano, J.; Kalionis, B.; Chrzanowski, W. Extracellular vesicles, exosomes and shedding vesicles in regenerative medicine-a new paradigm for tissue repair. Biomater. Sci. 2018, 6, 60-78. [CrossRef]

44. Silva, A.M.; Teixeira, J.H.; Almeida, M.I.; Goncalves, R.M.; Barbosa, M.A.; Santos, S.G. Extracellular vesicles: Immunomodulatory messengers in the context of tissue repair/regeneration. Eur. J. Pharm. Sci. 2017, 98, 86-95. [CrossRef]

45. Carrasco, E.; Soto-Heredero, G.; Mittelbrunn, M. The role of extracellular vesicles in cutaneous remodeling and hair follicle dynamics. Int. J. Mol. Sci. 2019, 20, 2758. [CrossRef] [PubMed]

46. Kucharzewski, M.; Rojczyk, E.; Wilemska-Kucharzewska, K.; Wilk, R.; Hudecki, J.; Los, M.J. Novel trends in application of stem cells in skin wound healing. Eur. J. Pharmacol. 2019, 843, 307-315. [CrossRef] [PubMed]

47. Liu, J.; Yan, Z.; Yang, F.; Huang, Y.; Yu, Y.; Zhou, L.; Sun, Z.; Cui, D.; Yan, Y. Exosomes derived from human umbilical cord mesenchymal stem cells accelerate cutaneous wound healing by enhancing angiogenesis through delivering angiopoietin-2. Stem Cell Rev. Rep. 2021, 17, 305-317. [CrossRef] [PubMed]

48. Kim, K.; Gil, M.; Dayem, A.A.; Choi, S.; Kang, G.-H.; Yang, G.-M.; Cho, S.; Jeong, Y.; Kim, S.J.; Seok, J. Improved isolation and culture of urine-derived stem cells (USCs) and enhanced production of immune cells from the USC-derived induced pluripotent stem cells. J. Clin. Med. 2020, 9, 827. [CrossRef]

49. Bruckova, L.; Soukup, T.; Visek, B.; Moos, J.; Moosova, M.; Pavelkova, J.; Rezabek, K.; Kucerova, L.; Micuda, S.; Brcakova, E. Proliferative potential and phenotypic analysis of long-term cultivated human granulosa cells initiated by addition of follicular fluid. J. Assist. Reprod. Genet. 2011, 28, 939-950. [CrossRef] 
50. Livak, K.J.; Schmittgen, T.D. Analysis of relative gene expression data using real-time quantitative PCR and the $2-\Delta \Delta C T$ method. Methods 2001, 25, 402-408. [CrossRef]

51. Shelke, G.V.; Lässer, C.; Gho, Y.S.; Lötvall, J. Importance of exosome depletion protocols to eliminate functional and RNAcontaining extracellular vesicles from fetal bovine serum. J. Extracell. Vesicles 2014, 3, 24783. [CrossRef]

52. Debacq-Chainiaux, F.; Erusalimsky, J.D.; Campisi, J.; Toussaint, O. Protocols to detect senescence-associated beta-galactosidase (SA- $\beta$ gal) activity, a biomarker of senescent cells in culture and in vivo. Nat. Protoc. 2009, 4, 1798. [CrossRef]

53. Gebäck, T.; Schulz, M.M.P.; Koumoutsakos, P.; Detmar, M. TScratch: A novel and simple software tool for automated analysis of monolayer wound healing assays: Short Technical Reports. Biotechniques 2009, 46, 265-274. [CrossRef]

54. Benavides, F.; Oberyszyn, T.M.; VanBuskirk, A.M.; Reeve, V.E.; Kusewitt, D.F. The hairless mouse in skin research. J. Dermatol. Sci. 2009, 53, 10-18. [CrossRef]

55. Liu, G.; Liao, C.; Chen, X.; Wu, Y. In Vitro and In Vivo Osteogenesis of Human Orbicularis Oculi Muscle-Derived Stem Cells. Tissue Eng. Regen. Med. 2018, 15, 445-452. [CrossRef]

56. Haniffa, M.A.; Collin, M.P.; Buckley, C.D.; Dazzi, F. Mesenchymal stem cells: The fibroblasts' new clothes? Haematologica 2009, 94, 258-263. [CrossRef] [PubMed]

57. Liu, R.; Chang, W.; Wei, H.; Zhang, K. Comparison of the biological characteristics of mesenchymal stem cells derived from bone marrow and skin. Stem Cells Int. 2016, 2016, 3658798. [CrossRef] [PubMed]

58. Vaculik, C.; Schuster, C.; Bauer, W.; Iram, N.; Pfisterer, K.; Kramer, G.; Reinisch, A.; Strunk, D.; Elbe-Bürger, A. Human dermis harbors distinct mesenchymal stromal cell subsets. J. Investig. Dermatol. 2012, 132, 563-574. [CrossRef]

59. Bae, S.; Shim, S.H.; Park, C.W.; Son, H.K.; Ju Lee, H.; Son, J.Y.; Jeon, C.; Kim, H. Combined omics analysis identifies transmembrane 4 L6 family member 1 as a surface protein marker specific to human mesenchymal stem cells. Stem Cells Dev. 2011, 20, 197-203. [CrossRef] [PubMed]

60. Lv, F.-J.; Tuan, R.S.; Cheung, K.M.; Leung, V.Y. Concise review: The surface markers and identity of human mesenchymal stem cells. Stem Cells 2014, 32, 1408-1419. [CrossRef] [PubMed]

61. Battula, V.L.; Treml, S.; Bareiss, P.M.; Gieseke, F.; Roelofs, H.; De Zwart, P.; Müller, I.; Schewe, B.; Skutella, T.; Fibbe, W.E. Isolation of functionally distinct mesenchymal stem cell subsets using antibodies against CD56, CD271, and mesenchymal stem cell antigen-1. Haematologica 2009, 94, 173-184. [CrossRef]

62. Holley, R.J.; Tai, G.; Williamson, A.J.; Taylor, S.; Cain, S.A.; Richardson, S.M.; Merry, C.L.; Whetton, A.D.; Kielty, C.M.; Canfield, A.E. Comparative quantification of the surfaceome of human multipotent mesenchymal progenitor cells. Stem Cell Rep. 2015, 4, 473-488. [CrossRef] [PubMed]

63. Théry, C.; Witwer, K.W.; Aikawa, E.; Alcaraz, M.J.; Anderson, J.D.; Andriantsitohaina, R.; Antoniou, A.; Arab, T.; Archer, F.; Atkin-Smith, G.K. Minimal information for studies of extracellular vesicles 2018 (MISEV2018): A position statement of the International Society for Extracellular Vesicles and update of the MISEV2014 guidelines. J. Extracell. Vesicles 2018, 7, 1535750. [CrossRef] [PubMed]

64. Wang, L.; Hu, L.; Zhou, X.; Xiong, Z.; Zhang, C.; Shehada, H.M.; Hu, B.; Song, J.; Chen, L. Exosomes secreted by human adipose mesenchymal stem cells promote scarless cutaneous repair by regulating extracellular matrix remodelling. Sci. Rep. 2017, 7, 1-12. [CrossRef]

65. Costin, B.R.; Plesec, T.P.; Kopplin, L.J.; Chundury, R.V.; McBride, J.M.; Levine, M.R.; Perry, J.D. Regional Variations in Orbicularis Oculi Histology. Ophthalmic Plast. Reconstr. Surg. 2015, 31, 325-327. [CrossRef] [PubMed]

66. Crapnell, K.; Blaesius, R.; Hastings, A.; Lennon, D.P.; Caplan, A.I.; Bruder, S.P. Growth, differentiation capacity, and function of mesenchymal stem cells expanded in serum-free medium developed via combinatorial screening. Exp. Cell Res. 2013, 319, 1409-1418. [CrossRef]

67. Katsuda, T.; Kosaka, N.; Takeshita, F.; Ochiya, T. The therapeutic potential of mesenchymal stem cell-derived extracellular vesicles. Proteomics 2013, 13, 1637-1653. [CrossRef]

68. Park, K.-S.; Bandeira, E.; Shelke, G.V.; Lässer, C.; Lötvall, J. Enhancement of therapeutic potential of mesenchymal stem cell-derived extracellular vesicles. Stem Cell Res. Ther. 2019, 10, 288. [CrossRef]

69. Huang, Y.-C.; Lai, L.-C. The potential roles of stem cell-derived extracellular vesicles as a therapeutic tool. Ann. Transl. Med. 2019, 7, 693. [CrossRef]

70. Tang, T.-T.; Wang, B.; Lv, L.-L.; Liu, B.-C. Extracellular vesicle-based Nanotherapeutics: Emerging frontiers in anti-inflammatory therapy. Theranostics 2020, 10, 8111. [CrossRef]

71. Cao, G.; Chen, B.; Zhang, X.; Chen, H. Human Adipose-Derived Mesenchymal Stem Cells-Derived Exosomal microRNA-19b Promotes the Healing of Skin Wounds Through Modulation of the CCL1/TGF- $\beta$ Signaling Axis. Clin. Cosmet. Investig. Dermatol. 2020, 13, 957-971. [CrossRef]

72. Hao, Y.; Miao, J.; Liu, W.; Cai, K.; Huang, X.; Peng, L. Mesenchymal Stem Cell-Derived Exosomes Carry MicroRNA-125a to Protect Against Diabetic Nephropathy by Targeting Histone Deacetylase 1 and Downregulating Endothelin-1. Diabetes Metab. Syndr. Obes. Targets Ther. 2021, 14, 1405. [CrossRef]

73. Vlassov, A.V.; Magdaleno, S.; Setterquist, R.; Conrad, R. Exosomes: Current knowledge of their composition, biological functions, and diagnostic and therapeutic potentials. Biochim. Et Biophys. Acta (BBA)-Gen. Subj. 2012, 1820, 940-948. [CrossRef]

74. Ramirez, M.I.; Amorim, M.G.; Gadelha, C.; Milic, I.; Welsh, J.A.; Freitas, V.M.; Nawaz, M.; Akbar, N.; Couch, Y.; Makin, L. Technical challenges of working with extracellular vesicles. Nanoscale 2018, 10, 881-906. [CrossRef] 
75. Ratajczak, J.; Miekus, K.; Kucia, M.; Zhang, J.; Reca, R.; Dvorak, P.; Ratajczak, M. Embryonic stem cell-derived microvesicles reprogram hematopoietic progenitors: Evidence for horizontal transfer of mRNA and protein delivery. Leukemia 2006, 20, 847-856. [CrossRef]

76. Luga, V.; Zhang, L.; Viloria-Petit, A.M.; Ogunjimi, A.A.; Inanlou, M.R.; Chiu, E.; Buchanan, M.; Hosein, A.N.; Basik, M.; Wrana, J.L. Exosomes mediate stromal mobilization of autocrine Wnt-PCP signaling in breast cancer cell migration. Cell 2012, 151, 1542-1556. [CrossRef]

77. Gross, J.C.; Chaudhary, V.; Bartscherer, K.; Boutros, M. Active Wnt proteins are secreted on exosomes. Nat. Cell Biol. 2012, 14, 1036-1045. [CrossRef] [PubMed]

78. Feng, Y.; Huang, W.; Meng, W.; Jegga, A.G.; Wang, Y.; Cai, W.; Kim, H.W.; Pasha, Z.; Wen, Z.; Rao, F. Heat shock improves Sca-1+ stem cell survival and directs ischemic cardiomyocytes toward a prosurvival phenotype via exosomal transfer: A critical role for HSF1/miR-34a/HSP70 pathway. Stem Cells 2014, 32, 462-472. [CrossRef]

79. Ong, S.-G.; Lee, W.H.; Huang, M.; Dey, D.; Kodo, K.; Sanchez-Freire, V.; Gold, J.D.; Wu, J.C. Cross talk of combined gene and cell therapy in ischemic heart disease: Role of exosomal microRNA transfer. Circulation 2014, 130, S60-S69. [CrossRef] [PubMed]

80. Yin, J.; Ge, X.; Shi, Z.; Yu, C.; Lu, C.; Wei, Y.; Zeng, A.; Wang, X.; Yan, W.; Zhang, J. Extracellular vesicles derived from hypoxic glioma stem-like cells confer temozolomide resistance on glioblastoma by delivering miR-30b-3p. Theranostics 2021, 11, 1763. [CrossRef] [PubMed]

81. Prattichizzo, F.; Matacchione, G.; Giuliani, A.; Sabbatinelli, J.; Olivieri, F.; de Candia, P.; De Nigris, V.; Ceriello, A. Extracellular vesicle-shuttled miRNAs: A critical appraisal of their potential as nano-diagnostics and nano-therapeutics in type 2 diabetes mellitus and its cardiovascular complications. Theranostics 2021, 11, 1031. [CrossRef]

82. Xia, B.; Gao, J.; Li, S.; Huang, L.; Zhu, L.; Ma, T.; Zhao, L.; Yang, Y.; Luo, K.; Shi, X. Mechanical stimulation of Schwann cells promote peripheral nerve regeneration via extracellular vesicle-mediated transfer of microRNA 23b-3p. Theranostics 2020, 10, 8974. [CrossRef] [PubMed]

83. Dong, J.; Li, L.; Fang, X.; Zang, M. Exosome-Encapsulated microRNA-127-3p Released from Bone Marrow-Derived Mesenchymal Stem Cells Alleviates Osteoarthritis Through Regulating CDH11-Mediated Wnt/ $\beta$-Catenin Pathway. J. Pain Res. 2021, 14, 297. [CrossRef] [PubMed]

84. Zhou, Y.; Zhu, Y.; Dong, X.; Cao, G.; Li, Y.; Fan, Y.; Chen, Q.; Cai, H.; Wu, Y. Exosomes Derived from Pancreatic Cancer Cells Induce Osteoclast Differentiation Through the miR125a-5p/TNFRSF1B Pathway. OncoTargets Ther. 2021, 14, 2727. [CrossRef]

85. Tran, P.H.; Xiang, D.; Nguyen, T.N.; Tran, T.T.; Chen, Q.; Yin, W.; Zhang, Y.; Kong, L.; Duan, A.; Chen, K. Aptamer-guided extracellular vesicle theranostics in oncology. Theranostics 2020, 10, 3849. [CrossRef] [PubMed]

86. Liang, Y.; Duan, L.; Lu, J.; Xia, J. Engineering exosomes for targeted drug delivery. Theranostics 2021, 11, 3183. [CrossRef] [PubMed]

87. Walker, S.; Busatto, S.; Pham, A.; Tian, M.; Suh, A.; Carson, K.; Quintero, A.; Lafrence, M.; Malik, H.; Santana, M.X. Extracellular vesicle-based drug delivery systems for cancer treatment. Theranostics 2019, 9, 8001. [CrossRef]

88. Zhang, K.; Dong, C.; Chen, M.; Yang, T.; Wang, X.; Gao, Y.; Wang, L.; Wen, Y.; Chen, G.; Wang, X. Extracellular vesicle-mediated delivery of miR-101 inhibits lung metastasis in osteosarcoma. Theranostics 2020, 10, 411. [CrossRef]

89. Chen, P.; Wang, L.; Fan, X.; Ning, X.; Yu, B.; Ou, C.; Chen, M. Targeted delivery of extracellular vesicles in heart injury. Theranostics 2021, 11, 2263. [CrossRef]

90. Villa, A.; Garofalo, M.; Crescenti, D.; Rizzi, N.; Brunialti, E.; Vingiani, A.; Belotti, P.; Sposito, C.; Franzè, S.; Cilurzo, F. Transplantation of autologous extracellular vesicles for cancer-specific targeting. Theranostics 2021, 11, 2034. [CrossRef]

91. Mousavinejad, M.; Andrews, P.W.; Shoraki, E.K. Current biosafety considerations in stem cell therapy. Cell J. 2016, 18, 281.

92. Kishore, R.; Khan, M. More than tiny sacks: Stem cell exosomes as cell-free modality for cardiac repair. Circ. Res. 2016, 118, 330-343. [CrossRef] [PubMed]

93. Li, N.; Zhao, L.; Wei, Y.; Ea, V.L.; Nian, H.; Wei, R. Recent advances of exosomes in immune-mediated eye diseases. Stem Cell Res. Ther. 2019, 10, 278. [CrossRef]

94. Klingeborn, M.; Dismuke, W.M.; Rickman, C.B.; Stamer, W.D. Roles of exosomes in the normal and diseased eye. Prog. Retin. Eye Res. 2017, 59, 158-177. [CrossRef]

95. Gonzalez, E.; Falcón-Pérez, J.M. Cell-derived extracellular vesicles as a platform to identify low-invasive disease biomarkers. Expert Rev. Mol. Diagn. 2015, 15, 907-923. [CrossRef]

96. Zhang, W.; Wang, Y.; Kong, Y. Exosomes derived from mesenchymal stem cells modulate miR-126 to ameliorate hyperglycemiainduced retinal inflammation via Targeting HMGB1. Investig. Ophthalmol. Vis. Sci. 2019, 60, 294-303. [CrossRef]

97. Moisseiev, E.; Anderson, J.D.; Oltjen, S.; Goswami, M.; Zawadzki, R.J.; Nolta, J.A.; Park, S.S. Protective effect of intravitreal administration of exosomes derived from mesenchymal stem cells on retinal ischemia. Curr. Eye Res. 2017, 42, 1358-1367. [CrossRef]

98. Samaeekia, R.; Rabiee, B.; Putra, I.; Shen, X.; Park, Y.J.; Hematti, P.; Eslani, M.; Djalilian, A.R. Effect of human corneal mesenchymal stromal cell-derived exosomes on corneal epithelial wound healing. Investig. Ophthalmol. Vis. Sci. 2018, 59, 5194-5200. [CrossRef]

99. Kim, Y.-J.; mi Yoo, S.; Park, H.H.; Lim, H.J.; Kim, Y.-L.; Lee, S.; Seo, K.-W.; Kang, K.-S. Exosomes derived from human umbilical cord blood mesenchymal stem cells stimulates rejuvenation of human skin. Biochem. Biophys. Res. Commun. 2017, 493, 1102-1108. [CrossRef] [PubMed] 
100. Oh, M.; Lee, J.; Kim, Y.J.; Rhee, W.J.; Park, J.H. Exosomes Derived from Human Induced Pluripotent Stem Cells Ameliorate the Aging of Skin Fibroblasts. Int. J. Mol. Sci. 2018, 19, 1715. [CrossRef]

101. Hu, L.; Wang, J.; Zhou, X.; Xiong, Z.; Zhao, J.; Yu, R.; Huang, F.; Zhang, H.; Chen, L. Exosomes derived from human adipose mensenchymal stem cells accelerates cutaneous wound healing via optimizing the characteristics of fibroblasts. Sci. Rep. 2016, 6, 32993. [CrossRef] [PubMed]

102. Gallet, R.; Dawkins, J.; Valle, J.; Simsolo, E.; De Couto, G.; Middleton, R.; Tseliou, E.; Luthringer, D.; Kreke, M.; Smith, R.R. Exosomes secreted by cardiosphere-derived cells reduce scarring, attenuate adverse remodelling, and improve function in acute and chronic porcine myocardial infarction. Eur. Heart J. 2017, 38, 201-211. [CrossRef]

103. Bodega, G.; Alique, M.; Puebla, L.; Carracedo, J.; Ramírez, R.M. Microvesicles: ROS scavengers and ROS producers. J. Extracell. Vesicles 2019, 8, 1626654. [CrossRef] [PubMed]

104. Waghule, T.; Singhvi, G.; Dubey, S.K.; Pandey, M.M.; Gupta, G.; Singh, M.; Dua, K. Microneedles: A smart approach and increasing potential for transdermal drug delivery system. Biomed. Pharmacother. 2019, 109, 1249-1258. [CrossRef] [PubMed]

105. Hearing, V.J. Biogenesis of pigment granules: A sensitive way to regulate melanocyte function. J. Dermatol. Sci. 2005, 37, 3-14 [CrossRef] [PubMed]

106. Briganti, S.; Camera, E.; Picardo, M. Chemical and instrumental approaches to treat hyperpigmentation. Pigment. Cell Res. 2003, 16, 101-110. [CrossRef]

107. Yasui, H.; Sakurai, H. Age-dependent generation of reactive oxygen species in the skin of live hairless rats exposed to UVA light. Exp. Dermatol. 2003, 12, 655-661. [CrossRef]

108. Yamakoshi, J.; Otsuka, F.; Sano, A.; Tokutake, S.; Saito, M.; Kikuchi, M.; Kubota, Y. Lightening effect on ultraviolet-induced pigmentation of guinea pig skin by oral administration of a proanthocyanidin-rich extract from grape seeds. Pigment. Cell Res. 2003, 16, 629-638. [CrossRef]

109. Kao, Y.-Y.; Chuang, T.-F.; Chao, S.-H.; Yang, J.-H.; Lin, Y.-C.; Huang, H.-Y. Evaluation of the antioxidant and melanogenesis inhibitory properties of pracparatum mungo (lu-do huang). J. Tradit. Complementary Med. 2013, 3, 163-170. [CrossRef] 